\title{
A qualitative study of men's perceptions \\ and attitudes towards weight management \\ and weight management services
}

\author{
Public Health Nutrition MSc \\ Paula Thorp \\ Student Number 0517487
}

October 2011 


\section{Acknowledgements}

Thank you to the following people for all your support.

Dr. Basma Ellahi, for the last six years and for the opportunity she gave me to complete an MSc in Public Health Nutrition.

Graham Garnett and Julia Hope at Chester West and Cheshire Council who facilitated the study at their workplace.

Each participant that took the time to take part in the interviews, without whom the study would not have been possible.

My employer, NHS Western Cheshire, especially my manager Gail Peters and my colleagues at Step by Step. Also special thanks also to Phil Elliott, Research and Development Manager for his help in analysing the data.

But most of all a huge thank you to my long suffering family for all your patience and support over the years. 


\section{Abstract}

\section{Aims}

This study investigated men's perceptions and attitudes to weight management and weight management services.

\section{Design}

A qualitative study design used one-to-one interviews to gain insight into the thoughts and feelings of the participants involved. A semi-structured topic guide was prepared to help guide the encounter. The interviews were tape recorded and transcribed verbatim. Framework analysis was used to make sense of themes that emerged.

\section{Subjects}

An article was circulated on the intranet at a single local government workplace in Chester in the north west of England inviting men to take part in the study. Eleven white British men aged between 27 and 59 years of age were recruited.

\section{Findings}

The study found that weight management was viewed as important for health but the pursuit of a healthy body mass index was not a consideration for the majority of the men who set their own paramaters for a healthy weight.

Appearance and image were important motivators but the men noted that there did not seem to be pressure to conform to a particular ideal. Being able to take part in 
sports or activity to maintain fitness were very important to the participants and this became a problem when injuries were sustained, especially recurring ones.

Changing priorities along the lifecourse presented individuals with different challenges for managing their weight. An interesting concept raised was that maintaining one's health through a diet and exercise regime was seen as 'work'.

The men viewed weight management as a personal responsibility and would not attend the health service for support unless it was associated with other symptoms. They viewed traditional weight management practices such as calorie counting and weighing oneself in public as being aimed at women and preferred to put the emphasis on physical activity rather than diet when managing their weight.

Flexible and expert services were a key theme with the men seeking a personalised service that went beyond the general healthy eating and exercise messages in order to make it worth their while to attend.

\section{Conclusion}

This study illustrates that a 'one size fits all' approach will not be sufficient if services are to attract and engage men in health behaviour change.

Implications for practice are that weight management services should be accessible without the need for a health referral and offer a range of services to allow men to find the best fit for their lifestyle. They should make the most of current technology using the internet, mobile phone apps and other forms of 
communication. Services should be marketed creatively to remove the stigma from attending weight management services which are seen to be for women only.

Whilst developing services for men practitioners should consider the differences in men and women's attitudes to food and activity and tailor services accordingly.

For example, focusing on body composition and fat loss rather than weight alone and consider using incentives in some settings.

Three main areas for further research were identified. These were exploring further men's views on appearance and body image because this was a strong motivator for weight management; the implications of long term injuries caused by exercising on men's ability to manage their weight along the life course and the concept of health as work. 


\section{Declaration}

I hereby declare that work contained herewith is original and is entirely my own work (unless indicated otherwise). It has not been previously submitted in support of a Degree, qualification or other course.

Paula Thorp

Date. 


\section{Contents}

\section{Chapter 1: Introduction}

$\begin{array}{lll}1.1 & \text { Introduction } & 13\end{array}$

1.2 Literature Review 17

$\begin{array}{lll}1.3 & \text { Aims and Objectives } & 24\end{array}$

\section{Chapter 2: Methods}

$\begin{array}{lll}2.1 & \text { Design } & 25\end{array}$

$2.2 \quad$ Population and Subjects 25

$\begin{array}{lll}2.3 & \text { Procedures } & 27\end{array}$

2.4 Data Management and Data Analysis 29

\section{Chapter 3: Results}

$\begin{array}{lll}3.1 & \text { Background to results } & 31\end{array}$

3.1.1 Qualitative analysis of interview data 33

$\begin{array}{lll}3.2 & \text { Health } & 33\end{array}$

3.2.1 Morbidity (avoiding ill health) 34

3.2.2 Mortality (living longer) 35

$\begin{array}{lll}3.2 .3 & \text { Fitness } & 37\end{array}$

$\begin{array}{lll}3.2 .4 & \text { Injuries } & 38\end{array}$ 
$\begin{array}{lll}\text { 3.3.1 } & \text { Body composition } & 40\end{array}$

3.3.2 Label of obesity 41

$\begin{array}{lll}3.3 .3 & \text { Image } & 42\end{array}$

3.3.4 Comparison with others $\quad 43$

$\begin{array}{lll}3.4 & \text { Priorities } & 45\end{array}$

3.4.1 Work 45

3.4.2 Younger men - aged 25-35 years 46

3.4.3 Middle aged men - 35-50 years $\quad 47$

3.4.4 Older men - aged 50+ years $\quad 48$

3.4.5 Personal approaches to weight management 50

$\begin{array}{lll}\text { 3.4.5.1 Proactive approach } & 50\end{array}$

$\begin{array}{lll}\text { 3.4.5.2 Reactive approach } & 51\end{array}$

$\begin{array}{lll}\text { 3.4.5.3 Self discipline } & 52\end{array}$

3.4.5.4 External discipline $\quad 53$

3.5 Gender and methods of weight management 54

3.5.1 Perceptions of available services 56

$\begin{array}{lll}3.6 & \text { Seeking help } & 59\end{array}$

$\begin{array}{llr}\text { 3.6.1 Personal responsibility } & 59\end{array}$

$\begin{array}{lll}\text { 3.6.2 Health care services } & 60\end{array}$

3.6.3 Previous experience of seeking help 62

3.6.4 Other sources of help and information 64 
3.7 Preferred characteristics of a weight management service $\begin{array}{ll}\text { for men } & 65\end{array}$

$\begin{array}{lll}3.7 .1 & \text { Format } & 65\end{array}$

$\begin{array}{lll}\text { 3.7.2 Gender of deliverer } & 67\end{array}$

$\begin{array}{lll}\text { 3.7.3 Group versus individual service } & 68\end{array}$

\section{Chapter 4: Discussion}

$\begin{array}{lll}4.1 & \text { Introduction } & 72\end{array}$

4.1.2 Strengths and limitations of this study 72

4.1.3 Perceptions and attitudes towards weight

$\begin{array}{ll}\text { management } & 73\end{array}$

4.1.4 Identify at what stage men take up weight

management services and why

4.1.5 Explore barriers to attending weight

management services

4.1.6 Use the qualitative evidence to formulate

recommendations for service development to maximise accessibility and effectiveness

$\begin{array}{lll}4.2 & \text { Individual findings } & 74\end{array}$

4.2.1 Health 74

$\begin{array}{lll}\text { 4.2.2 Body mass index } & 75\end{array}$

$\begin{array}{lll}\text { 4.2.3 Incentives } & 76\end{array}$

$\begin{array}{lll}\text { 4.2.4 Fitness and injuries } & 77\end{array}$

$\begin{array}{lll}\text { 4.2.5 Appearance } & 77\end{array}$

$\begin{array}{lll}\text { 4.2.6 Priorities } & 79\end{array}$ 
$\begin{array}{lll}\text { 4.2.7 } & \text { Younger men } & 79\end{array}$

$\begin{array}{lll}\text { 4.2.8 } & \text { Middle aged men } & 80\end{array}$

$\begin{array}{lll}\text { 4.2.9 } & \text { Gender aware services } & 80\end{array}$

4.2.10 Seeking help for weight management 82

4.2.11 Preferred characteristics of a weight management service $\begin{array}{ll}\text { for men } & 84\end{array}$

4.2.12 Format $\quad 84$

4.3 Experience of men's health promotion in Australia 85

$\begin{array}{ll}\text { Chapter 5: Conclusions } & 87\end{array}$ 


\section{List of Tables}

$\begin{array}{lll}1.1 & \text { Classification of BMI } & 12\end{array}$

$\begin{array}{lll}1.2 & \text { NICE Risk Categories } & 13\end{array}$

3.1 Characteristics of participants - Age, Body Mass Index,

Index of Multiple Deprivation by area $\quad 31$ 


\section{List of Appendices}

$\begin{array}{ll}\text { 1. Topic Guide } & 100\end{array}$

2. Participant Information Sheet 102

2.1 Participant Consent Form 104

3 Participant Profile Questionnaire 105

4 The five stages of data analysis using the framework approach 107

5 Transcript of intranet article used to recruit study participants 108 


\section{Chapter 1 \\ Introduction}

\subsection{Introduction}

Overweight and obesity are terms that are used to refer to an abnormal or excessive fat accumulation that presents a risk to health. The most widely accepted method of measuring overweight and obesity is to calculate a person's body mass index (BMI). This is done by dividing a person's weight $(\mathrm{kg})$ by their height squared $\left(\mathrm{m}^{2}\right)$, (see Table 1.1) .

Table 1: Classification of BMI (WHO, 2000)

\begin{tabular}{|c|c|c|}
\hline Classification & BMI $(\mathrm{kg} /)$ & Health Risk \\
\hline Underweight & $\leq 18.5$ & $\begin{array}{c}\text { Low (but risk of other } \\
\text { clinical problems } \\
\text { increased) }\end{array}$ \\
\hline Normal range & $18.5-24.9$ & Average \\
\hline Overweight: & $\geq 25.0$ & Increased \\
\hline Pre-obese & $25.0-29.9$ & Moderate \\
\hline Obese class I & $30 .-34.9$ & Severe \\
\hline Obese class II & $35-39.9$ & Very severe \\
\hline Obese class III & $\geq 40.0$ & \\
\hline
\end{tabular}

However, BMI does need to be interpreted with caution as it is not a direct measure of fat, nor does it account for the distribution of body fat. For example, an athlete with a muscular body may fall into the overweight category but have low body fat. Conversely, someone with a normal weight may have an unhealthy level of fat deposited around their waist which is known to increase obesity related disease. Therefore, waist circumference is used in conjunction with BMI to determine health risk for people with a BMI below $35 \mathrm{~kg} / \mathrm{m}^{2}$, (see Table 1.2). 
Table 1.2 : NICE Risk Categories (NICE, 2006)

\begin{tabular}{|c|c|c|c|c|}
\hline $\begin{array}{l}\text { BMI } \\
\text { Classification }\end{array}$ & $\begin{array}{l}\text { Waist ci } \\
\text { Male } \\
\text { Female }\end{array}$ & $\begin{array}{l}\text { nference } \\
\text { Low } \\
<94 \mathrm{~cm} \\
<80 \mathrm{~cm}\end{array}$ & $\begin{array}{c}\text { High } \\
94 \mathrm{~cm}-102 \mathrm{~cm} \\
80 \mathrm{~cm}-88 \mathrm{~cm}\end{array}$ & $\begin{array}{c}\text { Very High } \\
>102 \mathrm{~cm} \\
>88 \mathrm{~cm}\end{array}$ \\
\hline Normal weight & \multirow{3}{*}{\multicolumn{2}{|c|}{$\begin{array}{c}\text { No increased risk } \\
\text { No increased risk } \\
\text { Increased risk }\end{array}$}} & No increased risk & Increased risk \\
\hline Overweight & & & Increased risk & High risk \\
\hline Obese I & & & High risk & Very high risk \\
\hline
\end{tabular}

Although there is academic literature that challenges the medicalised understandings of overweight and obesity per se as significant risk factors for illness and death (Gard \& Wright, 2005, Campos, 2006, Aphramor, 2005); BMI and its function as a predictor of disease is commonly applied in most countries.

Overweight and obesity are worldwide public health problems with the World Health Organisation projecting that by 2015 approximately 2.3 billion adults (age 15 years plus) will be overweight and over 700 million will be obese (WHO, 2006). A raised BMI is a major risk factor for non-communicable diseases such as heart disease and stroke, diabetes, musculoskeletal disorders such as osteoarthritis and some cancers.

In the United Kingdom the prevalence of overweight and obesity has almost trebled in the last thirty years with 1980 figures showing $6 \%$ of adult men and $8 \%$ of adult women being classified as obese in England (Blake et al., 2004). This is compared to more recent figures from 2008 that report almost a quarter of adults ( $24 \%$ of men and $25 \%$ of women) as obese, and $66 \%$ of men and $57 \%$ of women overweight including obese (Health and Social Care Information Centre, 2010). 
Projecting into the future, if obesity prevalence continues to rise at the same rate as it did between 1993 and 2004 it is predicted that by $201232.1 \%$ men and 31.0\% women will be obese. This is almost a third of all adults, equating to about 13 million people (Zaninotto, Head, Stamatakis, Wardle \& Mindell, 2008). By 2050 this could rise to $60 \%$ of men and $50 \%$ of women. If these projections are correct the costs of overweight and obesity to the National Health Service (NHS) could be $£ 6.5$ billion, with the wider cost to society being $£ 49.9$ billion (Butland et al., 2007).

On a local level, in the Western Cheshire Primary Care Trust (PCT) area, it has been estimated that there are 49,842 (23\%) obese adults (aged 16 years and over). A further 79,295 adults (37\%) are estimated to have an increased health risk due to a raised waist circumference. Of these totals, 58,077 are estimated to be men, making up $44.9 \%$ of the population under consideration (Western Cheshire PCT, 2007).

In 2008, NHS Western Cheshire commissioned an adult weight management programme - Step by Step Healthy Weight and Lifestyle Programme - to target obese individuals in the area. The programme is a free, referral-based service which currently provides a six month group programme for adults with a BMI over $30 \mathrm{~kg} / \mathrm{m}^{2}$. At the time of the study, sessions comprised fortnightly nutrition information and behaviour change support with weekly physical activity classes. 
Statistics show that overweight and obesity are just as prevalent in men as in women and yet in practice men made up only $25 \%$ of attendees in the first year of Step by Step (Annual Report, 2009).

Despite men seeming to have just as great a need to manage their weight as women, they do not appear to be accessing those services which are currently available to them. 


\subsection{Literature Review}

Statistics show that men consistently have a lower life expectancy than women (Office of National Statistics, 2009; Courtenay, 2000) . Men are less likely to engage with health services, "men are less likely [than women] to visit a doctor when they are ill and are less likely to report on the symptoms of disease or illness" (Department of Health, 2000). "Traditional male attitudes" can have an adverse impact on men's health, in particular, "being independent", "not asking for help" and "being self-contained" (Health Development Agency, 2002). With regard to physical health, evidence from the United Kingdom shows that men use primary health care services (and GPs in particular) to a lesser extent than women (Cook et al 1990; NHS Executive 1998; Office of National Statistics, 2009).

However, this can be seen as an oversimplification of the situation as there is also evidence that women will delay help-seeking, for example in relation to myocardial infarction and cancer (MacIntyre et al, 1996). A qualitative synthesis of 32 papers reporting help-seeking experiences for different types of cancer, found that men associated consultation for illness with weakness and often legitimised helpseeking if their symptoms started to affect their ability to work. Women in contrast were more likely to cite prioritising work and family needs over their own health for their delay (Smith, Pope \& Botha, 2005). A literature review on gender differences in the early detection of cancer (Evans, Brotherstone, Miles and Wardle, 2005) found that some men may be as interested as women in attending cancer screening. Therefore the picture is mixed, with both sexes potentially delaying help-seeking but for different reasons. Of course this behaviour was 
observed in the context of cancer help-seeking and cannot be applied across all help-seeking.

Understanding gender differences is a starting point for finding out about men and women's differing help-seeking behavioural patterns but research needs to investigate further to inform the development of health care interventions, practice or policy that will better engage men with health care services (Galdas, 2009). More relevant is knowledge about gender specific processes that underlie men's and women's decision-making and resulting help-seeking behaviour. Research is beginning to show that relative under-utilisation of health care services is not uniform for all men. In order to understand why some groups of men have difficulty in seeking and accessing medical help and how gender affects helpseeking decision-making (Connell, 1995), it is necessary to focus investigations on men's experiences of seeking help and their views on how their weight affects their health.

A much cited paper by Mansfield, Addis and Mahalik (2003) sought to review the evidence supporting the view that men rarely seek help and why. They point to three main bodies of theory and research that may help to understand the phenomenon. In summary these are masculine gender socialisation, social psychological perspectives and social constructionist theory.

Masculine gender socialisation theory suggests that social environments from culture down to individual and family relationships teach men to display distinct gender-typed behaviours and attitudes through the adoption of norms and stereotypes. A norm is an expectation of how men should behave and a stereotype 
is a generalisation about what men are like. That is, societal and personal beliefs about what it means to be a man. Gender-role conflict occurs when living up to these norms conflicts with how a man really feels, for example not expressing emotions in public.

Social psychological theory identifies factors that have been shown to be related to help-seeking attitudes and behaviour. The paper identifies five social psychological concepts which may influence men's help-seeking. Briefly these are normativeness, ego-centrality, conformity, reactance and reciprocity.

Social constructionist theory puts forward the belief that gender is not a trait or personal characteristic but the acting out of masculinity and that this may differ depending on context. For example, there may be a widespread reluctance to seek or be seen seeking help in many men but a firefighter may have no hesitation about consulting to maintain his health because in doing so he can maintain his strong masculine identity through his job. A 'hierarchy of threats' to masculinity has been suggested where in some situations help seeking can preserve masculine status rather than threaten it, such as consulting for a sexual health problem rather than running the greater risk of not being able to have sex (O'Brien, Hunt \& Hart, 2005).

Alternatively, a literature review on men and health help-seeking behaviour (Galdas, 2005) also points to a significant body of research that argues against gender being a determining factor in help-seeking behaviour. Here the research points to occupational grade having more relevance as a predictor of variables in 
help-seeking behaviour. Other research cited in this paper reports that there is little difference between men and women. The paper concludes that there are significant gaps in the research evidence and that future investigations need to focus on the influence of masculine beliefs and the variations between men of differing socio-economic status, age and ethnicity.

Additionally, research into men's approaches to seeking help specifically for weight management highlights other factors to take into account. McCreary and Sadava (2001) sent a questionnaire to men and women and found that a significant proportion of overweight men saw themselves as normal weight compared with normal or underweight women who saw themselves as overweight. Similarly, overweight men rated themselves as more attractive and healthier than women who were overweight. Other studies (Wardle \& Johnson, 2002; Rosmond \& Bjorntorp, 2000) echo these findings with men either not recognising that they are overweight or those with a body mass index over 25 (overweight) actually reporting a better home-family situation, appetite and self-esteem, respectively. It is also proposed that bodyweight misconceptions are compounded by societal stereotypes that expect women to be thin and men to be bulky and muscular. A further paper (Ziebland, Robertson, Jay and Neil, 2002) explored body image and weight change in middle age and found that men were described as less worried about weight gain partly because it is more acceptable for a man to be larger and muscled and partly because women are thought to be more accepting of weight gain in their male partners. This study also found that respondents did not think it likely that they would be able to control their weight without making a big effort, although interestingly most did not believe that weight gain in middle age was inevitable. 
Research into what might motivate men to seek treatment and which treatment characteristics would appeal to them is limited. Early studies such as that of Egger and Mowbray (1993) ran focus groups with blue-collar workers in Australia and found that men wanted to lose weight to 'feel better', health and appearance were not mentioned. However the participants did report disatisfaction with their weight and that they wanted to lose weight. Another study asked what would help them to achieve weight loss and they asked for an individualised programme that would not expect them to give up alcohol, take up strenuous exercise or focus on psychological issues (Egger, 2000). Hakala, Karvetti and Ronnemaa (1993) compared the effectiveness of group and individual counselling with a Finnish sample of men and women taking part in a two year programme and found that men had a notably better weight loss outcome with an individual counselling approach. In contrast a Swedish study (Anderson \& Rossner, 1997) designed a male-only group programme that met weekly for two years focusing on nutrition, exercise and eating behaviours. It encouraged a weekly 'extravagance' and also offered options for individualisation such as additional classes or private sessions. Adherence was good with $66 \%$ of the 86 men recruited still actively involved and achieving modest weight loss at the end of the progamme.

A more recent study in America (Wolfe and Smith, 2002) surveyed 72 overweight men to find out what reasons might make them want to lose weight. For this group health and appearance were the main motivators along with negative health events. The researchers suggest that this may be due to their sample population tending to be white collar workers and drawn from a health care setting. $38.9 \%$ of the men surveyed preferred a gym or fitness centre and $31.9 \%$ an at-home programme 
whereas traditional programme settings such as medical, commercial or psychology clinics were poorly supported. An individual approach was again endorsed with $33 \%$ indicating a desire to work one to one with a weight loss counsellor. Perhaps not surprisingly the preference was for individual attention and minimal lifestyle disruption.

There is a paucity of studies evaluating existing men's weight management programmes, possibly because there are not many in operation, but there are some. A recently published paper (Gray et al, 2009) evaluated the first four years of a men only group-based weight management programme in Scotland. The programme used a men's health check clinic to raise awareness of overweight and obesity and those with a body mass index over 30 (obese) were invited to join the weight management programme. This label of obesity seemed to be powerful in motivating the men to join the programme and also the fact that it was men only was seen as an important factor. The men also reported joining the programme because they knew it was not a diet and because of pressure from family members. Over three-quarters of the men who started the 12 week programme completed it, with $44 \%$ achieving more than $5 \%$ weight loss. This study would seem to suggest that a group based programme is not only acceptable to men but actually a successful model that could potentially be used in other settings.

A study (Bye, Avery \& Lavin, 2005) commissioned by Slimming World, a commercial weight loss organisation, evaluated data from it's men only slimming groups which had been designed to address the fact that in 2002 their average male attendance was only $3 \%$. The men only groups were run on the same basis as the 
mixed groups providing weekly support and nutrition advice. The groups operate on an open basis and continue indefinitely. $90 \%$ of 67 participants lost between $5 \%$ and $10 \%$ of their initial weight within 3-6 months of starting the programme. This would again suggest that men are able to cope with group settings and benefit from a group approach.

A number of documents exist summarising the breadth and depth of the issues relating to gender health inequalities. A noticeable contributor to the field is the Men's Health Forum which is a charity "seeking to provide an independent and authoritative voice for male health.” It produced a policy report (Men's Health Forum, 2005) that identifies how little developed knowledge is available on how to engage with men about their weight. Following their conference, 'Hazardous Waist?' in 2005, they developed an action plan making specific recommendations. These included raising awareness that weight is a male issue too, building a research base into men's attitudes to weight and weight loss, an increased investment in 'male-sensitive' approaches particularly in primary care and health promotion and the development of effective ways of working with boys on weight issues for prevention. Since then they have been commissioned by the Department of Health to undertake a study into the different ways men and women engage with health services to help determine key gender health priorities for the Department of Health and National Health Service (Men's Health Forum, 2008). The recommendations from this report continue to highlight the need for more gender specific research in the field of weight management, the collation of sex-aggregated data and gender specific Public Service Agreements from government to ensure efforts and resources are directed appropriately. 
The problem of engaging men must also be seen along side the broader question of how to engage anybody in health behaviour change. The Department of Health's Ambitions for Change document (DH, 2008) sets out a framework for maximising the potential of social marketing and health-related behaviour.

There is clearly a need for sensitive and focused research into men's approaches to health to avoid perpetuating health inequalities attributed to gender. It is essential that study designs take into account the multi-layered nature of help-seeking decision making and the differences amongst men to provide good quality data.

\subsection{Aims and Objectives}

The proposed study aims to fulfil this criteria by speaking to men directly to investigate their perceptions and attitudes towards weight management and weight management services.

The study objectives are:-

- Investigate perceptions and attitudes towards weight management

- Identify at what stage men take up weight management services and why

- Explore barriers to attending weight management services

- Use the qualitative evidence to formulate recommendations for service development to maximise accessibility and effectiveness 


\section{Chapter 2}

\section{Methods}

\subsection{Design}

The study was concerned with finding out what meanings the men attached to weight management and their experiences of it. The researcher also wanted to understand how the men saw weight management services in the context of their social world view. To achieve this a qualitative study design using semistructured one-to-one interviews was used as the most appropriate method because it allowed the gathering of in depth data from the men. Semi-structured interviews provided a loose structure of open-ended questions that initially defined the topic but also gave the interviewee the freedom to discuss new areas or ideas that may not have been anticipated by the researcher. This method allowed the researcher to explore in detail the layers of understanding the men attached to weight management rather than staying at a superficial level. This was in keeping with the research aims and objectives of the study.

\subsection{Population and Subjects}

A workplace was chosen as the site for the study because of the potential for this type of setting to positively impact on health and weight (Cross-Government Obesity Unit, 2008). It also provided a central recruitment point and a convenient and accessible venue. Most importantly it allowed access to a cross section of men from a wide range of demographic backgrounds including access to both blue and white collar workers (previous research has shown occupational grade to be an important factor in health help-seeking decision making), different age groups, ethnicity and socio-economic status. 
Chester West and Cheshire Council (CWAC) was selected because it was located in the catchment area of NHS Western Cheshire and it's employees were indicative of the local population that were eligible to access NHS Western Cheshire's existing weight management programme. In addition, Cheshire West and Chester Council is committed to working in partnership with NHS Western Cheshire through the Local Strategic Partnership for Health and Wellbeing. The joint Health Inequalities Action Plan produced by the partnership aims to stop the rise of obesity by 2015 (West Cheshire Together, 2010). This study will provide needs assessment data that will be of direct relevance to achieving this target. The findings may also be applied to the development of men's weight management services in the local area and CWAC are potential partners in this, particularly if a workplace setting is to be employed.

Participants were recruited by an article circulated on the intranet (Appendix 5) which required them to contact the researcher to take part. They were not known to the researcher prior to this contact. This meant they were self-selected and able to give their consent freely. An information pack including a Participant Information Sheet (Appendix 3), Participant Consent Form (Appendix 2.1) and Participant Profile Questionnaire (Appendix 3) was given to those expressing interest.

Inclusion Criteria: Male, adult (over 18 years old), employed by workplace selected for study. A comparative study of men and women's attitudes to weight management and weight management services was considered but due to the need for data to be kept to manageable amounts for one researcher to collect and analyse 
it was thought better to concentrate on male participants only. It was considered that this would give a deeper insight and enable more male participants to take part than if the study was to include women as well.

Exclusion Criteria: Under 18s, women, respondents who have attended, are currently attending or planning to attend Step by Step Healthy Weight and Lifestyle Programme. Under 18s and women are not included for the reasons stated above. It was decided to exclude any Step by Step clients, past or present, to avoid bias as the researcher may be known to them or their views of weight management will have been influenced by their attendance on the programme.

Ethical approval was gained from the University of Chester Ethics Committee on $19^{\text {th }}$ June 2010. All participants gave their informed consent and were advised that they could withdraw from the study at any time without prejudice. Participants were not given payment or reimbursement of expenses for taking part in the study.

\subsection{Procedures}

Respondents' baseline demographic data was collected via the Participant Profile Questionnaire to help place the research in context and allow maximum diversity sampling. This was designed to allow comparisons of attitudes and perceptions amongst men.

The researcher planned to include men with a range of BMIs. Within each BMI category, the researcher would then assign participants to represent a mix of profiles based on sub-categories of age, ethnicity, family status, job role and family 
health status. During the study this stage was not possible due to low respondent numbers and therefore all respondents were included in the study, regardless of profile.

Once participants had contacted the researcher wanting to take part they were invited to attend a semi-structured interview and the information pack was sent out to them.

Semi-structured interviews took place in a private room on Council premises on a one-to-one basis between participant and researcher. A topic guide (Appendix 1) was prepared based on an examination of previous research in the subject area in order to identify areas of particular interest or relevance. However the guide was only used as a prompt and participants were given scope to expound on areas that were of particular resonance to themselves. The researcher piloted the topic guide for timing and usability with a family member prior to the interviews taking place.

The topic guide was used to draw out the men's views on a number of areas related to research findings previously described. These were attitudes to weight and health, influence of family and friends, concern about weight, past experiences of weight management/help-seeking and views on health services dealing with weight management.

Interviews lasted for between twenty-nine minutes and one hour, seventeen minutes. The interviews were tape recorded (with permission) and transcribed by Adele Herson's Typing Services. 
All personal identifiable data collected was kept securely in accordance with the Data Protection Act and destroyed on completion of the study. Anonymity was preserved with the use of pseudonyms.

\subsection{Data Management and Data Analysis}

The data was analysed using the framework approach for qualitative data analysis developed by the National Centre for Social Research as discussed by Pope, Ziebland and Mays (2006). This method is similar to thematic analysis but there are five stages in the process (Appendix 4). It was considered the most appropriate method because the aims and objectives for the study were set by the researcher with regard to the literature and the need to be able to apply the study's findings to the development of a local weight management service.

The researcher used field notes and observations during the period of data collection as recommended by Miles and Huberman (1994). This early analysis helped to clarify thoughts about existing data and the generation of new data from the interviews that followed. As each interview was transcribed the researcher started the process of reading and re-reading the data to identify initial themes. The data was then systematically searched for items of interest such as events or views that were common or contradictory. The data was coded and entered into an Excel spreadsheet to allow easy data retrieval.

As a starting point for the analysis, four main categories were created relating to the research questions. Sub-categories were then generated within these main 
categories to order the many sub-themes identified. During this process it became clear that there were cross cutting themes. Matrices were developed to illustrate the findings using headings such as 'motivations' or 'barriers to weight management' and the researcher also experimented with displaying the findings in relation to the topic guide themes but found that it was difficult to show a coherent picture. Initial drafts of the findings were shared with Dr Phil Elliott (Research and Development Manager, NHS Western Cheshire) and during discussions it became clear that it was important to consider comparisons between the men.

In searching for the best way to present the data the researcher referred to the Healthy Foundation Life-stage Segmentation tool kit (Department of Health, 2010) and a report commissioned by the Central Office of Information/Department of Health entitled 'Maximising the appeal of weight management services' (Rowe and Basi, 2010). Both of these pieces of research used a social marketing approach to identify groups of people within the population and consider how services could best promote health behaviour change to specific groups. These models helped to clarify a way of reporting the findings by using a synthesis of a person 'type' with 'characteristics' or a person profile as identified from the responses given by the men. Elements of this approach were incorporated into the final data analysis in the results section. 


\section{Chapter 3}

\section{Results}

\subsection{Background to results}

Response to the recruitment article was poor with seven interviews booked prior to the interview period. One participant cancelled on the day and this was rearranged but subsequently cancelled again so it was agreed to abandon the interview.

A further five interviewees were recruited during the interview period. Hard copies of the intranet article were put out in the breakout seating areas provided for lunch or breaks on each floor of the council's HQ building where interviews were taking place. This raised awareness on the day and was cited by two participants that were recruited on the day by the researcher by direct application. A remaining three participants were recruited following a reminder email that was circulated by the council member of staff that was facilitating the study on the day. The total number of participants was eleven.

All participants were men as required for the purposes of the study and all had the same ethnicity of white British. The average age was forty-two years with the oldest participants being fifty-nine, and the youngest twenty-seven. A range of body mass indices was represented). Participants lived in a range of socioeconomic areas as determined by their postcodes. These were mapped to the Indices of Multiple Deprivation (IMD) data which are ranked nationally into quintiles with addresses in quintile 1 being in the most deprived area and quintile 5 the least deprived. 
Table 3.1: Characteristics of participants - Age, Body Mass Index, Index of Multiple Deprivation by area

\begin{tabular}{|l|l|l|l|l|}
\hline Name* & Age & $\begin{array}{l}\text { IMD } \\
\text { Area }\end{array}$ & BMI & BMI Category \\
\hline Steve & 29 & Q2 & 26.3 & Overweight \\
\hline Chris & 44 & Q1 & 28.4 & Overweight \\
\hline Ian & 34 & Q4 & 30.9 & Obese I \\
\hline Alan & 47 & Q5 & 24.0 & $\begin{array}{l}\text { Healthy } \\
\text { Weight }\end{array}$ \\
\hline Andy & 39 & Q2 & 27.7 & Overweight \\
\hline Malcolm & 59 & Q1 & 29.6 & Overweight \\
\hline Phil & 50 & Q5 & 26.8 & Overweight \\
\hline Terry & 54 & Q3 & 28.6 & Overweight \\
\hline Jake & 27 & Q1 & 25.8 & Overweight \\
\hline Bill & 59 & Q5 & 39.3 & Obese I \\
\hline Rick & 30 & Q4 & 24.3 & $\begin{array}{l}\text { Healthy } \\
\text { Weight }\end{array}$ \\
\hline
\end{tabular}

*Names are pseudonyms to preserve anonymity of participants.

The majority of participants worked as Local Government Officers with primarily desk based jobs although at different levels of seniority and complexity of role. Only one had what could be described as a manual and routine job but was similarly sedentary in his role. 


\subsubsection{Qualitative analysis of interview data}

Following the framework analysis methodology, as previously described, the data were organised into six themes.

\subsection{Health}

Health was linked to weight for the majority of participants, but not all. It became clear from participants' responses that they attached different meanings to the word health. For some it was related to negative physical changes associated with weight gain such as increased snoring or physical discomfort and for others it was related to the ability to perform at a desired optimum level.

For some participants personal experience of ill health had led to a heightened awareness of the link between weight and health as described below:-

Life changing experience, twelve years ago diagnosed with diabetes...so from that time on I've been very conscious about my health and very strongly relate it to weight, it was the first time really that, if you like, a health problem had kicked in.

(Terry, 54)

The measure of body mass index was not seen as a motivation for weight management or an indicator for health. However, one participant did use it as a monitoring tool and was aiming for a goal weight in the healthy weight range. 


\subsubsection{Morbidity (avoiding ill health)}

Although body mass index as an indicator of health risk was largely ignored, the concept of preventing ill health for the future was a very strong motivator for some. This was particularly related to significant family members' health experiences.

Jake displayed a clear desire to 'store up' health for his old age so that his quality of life was not impaired.

I'm putting in the effort now and I'll get benefits later down the road...I'm very much into the health and longevity side of things...I want to build muscle and be bigger, etc. But that's because I believe like the more muscle I've got as I age, the more able-bodied I'd be...I see a lot of older people in my family and so on that's kind of withered away and you can see they struggle to hold themselves up and getting up and I think that's part of the key to having a better life as you're older.

(Jake, 27)

The men's acceptance of a general link between weight and health though can be inferred from the data with the exception of Ian and his experience of his mother's weight loss.

My mum's sort of weight, lost, she's probably lost over the last ten years probably easily six or seven stone just through changing her diet, but it hasn't helped her health...her health's not good, I 
wouldn't say it's bad health but it's not good, but it's just more things like allergies she suffers from, thing like that so... so I haven't, I've never really seen that [weight and health] as a sort of relationship. (Ian, 34)

The majority of participants did not explicitly refer to avoiding ill health as a motivation for their personal weight management but some did refer to living longer.

\subsubsection{Mortality (living longer)}

Mortality was discussed in terms of gaining years of life and was a key motivator for some. This approach appeared to be prompted by a 'taking stock' of health with milestone birthdays being referred to as catalysts for reviewing lifestyle as expressed by Phil.

Well I'm fifty this year, I am fifty, so I think it's even more important really to keep on going, you know...there's some factors you can have control over and why not do that, you know... like physical activity and so on and so forth, what you eat."

(Phil, 50)

The age that this took place varied amongst individuals but generally occurred past the age of 30 years. Reasons for 'taking stock' appeared to be related to family experiences of longevity or simply a recognition that the ageing process might make it harder to stay fit and healthy as in Malcolm's case. 
I've got high blood pressure...my two sisters got high blood pressure as well, my mum and dad, my dad did, my mum had a stroke...they've both passed away now...but, as I say, I'm coming up to sixty and I want to try and live a bit longer because they both died at seventy-nine years of age you see...I know people who lived to eighty-five, ninety so I'd like to try and see my grandchildren get married and have grandkids, great grandchildren.

(Malcolm, 59)

Not everyone expressed the thought of living longer as a motivator for weight management. For example, one overweight participant felt that perhaps his vegetarian diet would counterbalance this risk to his longevity to some degree, even if it may not always have been healthy.

I'm a vegetarian of twenty years and for the last five years I've not had any milk or dairy products...I just think that I'm not really usually polluting myself when I eat you know, ...I'm not eating any red meats, I'm not eating any fat, or animal fat...I've probably taken my eye off the ball really about the healthy content of what I'm eating, I'm quite, it might be misguided but I'm quite comfortable with that and I've got a relatively healthy diet really.

(Andy, 39) 
In summary, concern for quality of life in the future and living longer varied in importance as a motivator for weight management depending on the individual involved. Another motivating factor commonly mentioned was fitness.

\subsubsection{Fitness}

Fitness was seen as a more immediate and tangible benefit of successful weight management than general health. Some participants related fitness as an ability to cope well with the pressures of life and feeling good. For others fitness meant their ability to take part in a sport or physical activity that gave them enjoyment.

In fact, for at least one person feeling fit was the primary motivator, with maintaining a healthy weight being seen as a secondary outcome.

I try to do some form of physical exercise every day...it isn't much about weight, it's keeping fit...well personally it's just a feeling...if I don't do it I feel under par, I feel sluggish and a bit manic really...I would feel a bit down in the dumps, a bit agitated so I need to do it. (Phil, 50)

Conversely, lack of fitness was acting as a barrier for Malcolm. He knew what he wanted to do to improve his fitness and had a preferred method in mind, but did not feel confident enough to translate it into action by himself.

I used to enjoy swimming and I struggle to actually swim now... I get breathless quite easily...my chest tightens up and that. I don't 
think it's an illness or anything, I think it's just I'm carrying too much weight and so, so, I couldn't, I couldn't run, I probably couldn't even run fifty yards...I'd love to try a gym to be honest, I would really love to try on a treadmill or something like that, or even on the rowing machines...someone to give you a programme...not so that I didn't push myself too far, but just be enough to tone myself up a bit...

(Malcolm, 59)

Therefore it appears that where there is already a degree of fitness or an exercise routine in place, motivation is stronger because the individual concerned is able to experience the benefits on a daily basis. This means that individuals are more likely to prioritise exercising over other tasks and responsibilities in their lives.

By contrast, the goal of achieving fitness in the future is a weaker motivator perhaps because the desired benefit is seen as unattainable in the short term. Another barrier identified was injury.

\subsubsection{Injuries}

These were commonly reported as barriers to exercise, particularly joint problems and pulled muscles as related by Steve.

Full of injuries... bad knees and shin splints...when I do exercise I know that yeah, I'll be losing a bit of weight but I'm going to be in 
pain for a few weeks after doing it. So it's often difficult for me to exercise as much as I want to.

(Steve, 29)

Six out of the eleven participants had sustained training or sport related injuries, either in the past leading to a permanent problem or currently, to the degree that it affected their ability to continue training.

I can't actually physically do running because I've got a dodgy knee joint ... and that's actually a problem, that's probably the best one for me in terms of overall weight reduction and fitness and things...but I just can't actually do it.

$($ Ian, 34)

This suggests that injury may be a significant issue in male adult weight management, particularly in the younger and middle-aged groups. The injuries seemed to be largely associated with possible over-training, for example working too intensively or using incorrect technique. Being able to enjoy exercise was a key motivator for many participants. Frustration at not being able to do so due to injury therefore may have potential to de-motivate previously dedicated and proactive participants.

A sporting physique associated with continued training and other markers of a desired appearance were also described as motivators. 


\subsection{Appearance}

Appearance and the desire to look a certain way were driven by a variety of factors. These ranged from wanting to appear strong for sport, not wanting to be seen as obese, to be able to fit into a certain size of clothing, to fulfil a particular body image or to avoid stigmatism from the rest of society because of being overweight.

\subsubsection{Body composition}

Some participants were motivated by a desire to look healthy and muscular rather than to reach an ideal weight. This was noticeable in the men who had the highest activity levels and was expressed as working to achieve a preferred ratio of fat to muscle as explained by Jake.

I'm not sure so much my weight would correlate to how healthy I feel, it's more like my body composition like how much fat I've got on my body, how much muscle I've got on my body, I wouldn't want to be overly skinny or overly fat, I'd like have like a happy medium of being in between, like an athletic type of body.

(Jake, 27)

On a slightly different note, although Phil's body mass index fell into the overweight category he personally experienced good health and therefore rejected being labelled overweight.

Well, I've seen these charts [body mass index] before and I'm always in the reddish zone and I don't believe it, that I'm not 
overweight and the reason why I know I am not overweight because I'm very fit and I go down to the gym a lot... so I've got a bit of size on me due to the fact that I use a lot of weights but for example, every day I always run up the stairs here so I don't believe there's a health problem there.

(Phil, 50)

However, this rejection of the clinically defined term of overweight was not applied to obesity.

\subsubsection{Label of obesity}

Some felt that the label of obesity was less acceptable than the label of overweight. They explained how they would be more likely to take action to lose weight if they were told that they were obese. Terry's comments suggest that he has an image of himself that includes a degree of overweight but not obesity.

It doesn't bother me being in the overweight category because now that you've mentioned these classifications, that's where I guess I've been for a long time. I think I'd be pretty concerned if I was put in the obese... I've never really felt as though I've really either looked or felt poor for it, in fact to lose any further weight would have kind of not been me really.

(Terry, 54) 
A personally defined image was identified as a key motivator for participants to manage their weight.

\subsubsection{Image}

The participants' view of their physical image was shaped by wanting to be able to fit into clothes and achieve a particular look. This is illustrated by Steve and his aspiration towards achieving a footballer's body.

When I bought the new [football strip] shirt in the summer I realised ...I didn't have the footballer's body that I used to have, I've got a bit of a beer belly now, not all caused by beer, a lot is just down to food and exercise and stuff...my appearance in that shirt was different to the way for example, the footballer's you know got the flat sort of stomach. I thought I can't wear that so I don't really wear it very often.

(Steve, 29)

Two participants were prepared to consider more drastic measures to achieve their desired image even considering fat reduction surgery as discussed by Ian.

I'd always be interested in supplements or...the actual, the weight loss pill basically...if I got to the point where I sort of had bits I wanted to get rid of and weren't shifting, I would probably toy with liposuction...

(Ian, 34) 
This desired physical image was also related to comparison with peers or accepted societal norms for body shape.

\subsubsection{Comparison with others}

Comparison of appearance with others arose as a potential motivator although this depended on whether the comparison was favourable or not.

So your comparison is different depending on the group I suppose...If I went into a swimming camp, you see yourself differently because clearly there you've got people who could be like in their 60s who are still very athletic and stuff like that...so when you're in that sort of fitness type group, then I suppose there is motivation ... but ...when you go into the office environment and your average person, average 40 year old say, has got a bit of a pot belly and looks a little bit unfit, then you think 'I'm not doing that bad.'

(Alan, 47)

Interestingly, Alan also described his son's experience of a muscular body shape in comparison with peers (that is, a competitive swimmer's ' $V$ ' shape of broad shoulders and a narrow waist) and how it could give confidence and some protection from being picked on in school. 
Another variation on this theme was reported by Rick who described wanting to put on weight to achieve the necessary bulk and strength to take part in football and boxing. This was also the case for many of his peer group.

I've got friends who at this moment are deliberately trying to put as much weight on as possible, they're into training and are on all kinds of steroids and stuff...I'd say most of my friends want to put weight on.

(Rick, 30)

Bill identifies the desirability of a socially acceptable norm relating to appearance as he describes how he feels he is treated differently to the rest of society because he is overweight.

Well I used to have rows with a lad...at work all the time and I knew I'd won when he called me fatty, you know because people will always have a go at your weakness and being overweight has always been seen as a weakness...if you carry a bit of weight they'll always have a go at you with it.... it's the way I am at the moment and it's not that I want to be like this... (Bill, 59)

Bill's comments illustrate the social pressure felt when overweight and how an awareness of a weight problem alone is not enough to lead to action. Motivation 
and ability to prioritise healthy eating and exercise in daily life were identified as key issues.

\subsection{Priorities}

All of the participants, regardless of age, responsibilities or motivation reported having to cope with barriers to weight management. Work-life balance was mentioned as a common barrier for all.

\subsubsection{Work}

All participants had sedentary roles, which contributed to a challenging environment for successful weight management. Within the workplace, it was felt that healthy food provision was expensive. It was also felt that due to the inactive nature of the work it was harder to resist temptation for less healthy, cheaper foods.

The cost of not adhering to social norms was apparent again with Jake's experience in struggling to gain acceptance for his eating practices.

I'm basically eating like five or six meals a day in work, you get one lunchtime, so I was having three meals through the day every 3 hours, something like that and people didn't like that...you were a different person because of it and you don't get respect for it...luckily, there were a few other lads that were my age, they joined our office and they were like-minded and ate in a similar way.... now we're all doing it, I can have my meals at my desk, no one says anything now... it was upsetting and I forget about that, to be honest, but I had to struggle with that aspect (Jake, 27) 
These experiences highlight the impact of societal forces on health behaviour and how making healthy choices often means going against the norm.

Doubt was expressed that exercise opportunities on site would necessarily be taken up even if they were available. Conversely, others felt that they would take the opportunity to exercise in work if there was suitable provision.

During the interviews it became apparent that there were different sets of pressures on the men that could be related to stages along the life course. It was also possible to roughly segment these differences according to age groups.

\subsubsection{Younger men - aged 25-35 years}

The younger men in the study were either single or with a partner but had no children. Barriers were to do with balancing work, rest and play and maintaining relationships. Increased responsibility at work and the need to take work home to meet these responsibilities meant less time was available for exercise. This was coupled with greater affluence, which encouraged more eating out.

Jake crystallises the position with his view that maintaining one's health is work rather than leisure.

I guess it's the kind of 'work, rest and play' balance, because you count the gym and stuff like that as work as well and I'm trying to squeeze the 'play' in at the end and then not getting enough rest... I think definitely my time management would affect how I'd want to do things, if I didn't have to work in a day job... (Jake, 27) 


\subsubsection{Middle aged men - aged 35- 50 years}

The middle-aged men in the study were all married with children of varying ages and levels of dependence (e.g. from five years old to early twenties). Their time was taken up with childcare and family responsibilities and again maintaining personal relationships as evidenced by Andy's comments below:-

I used to play football three times a week you know, I don't want to go down the divorce route again, that would happen if I played three times a week.

(Andy, 39)

However, there was also a positive dimension to having dependents and that was that the men saw themselves as having a duty to be positive role models to their children. Their partners took the same approach and together they worked to support the whole family's health.

We've always had the children around the table. As I say, they're old, they're all adults now but we never sat in front of the TV with a tray on our lap and there's no TV in the kitchen. I think family influences are huge; parenting is a huge influence on future behaviour.

(Phil, 50) 


\subsubsection{Older men - aged 50+ years}

The older men all had partners and some had grown up children with grandchildren that made demands on their time. They were still juggling work and household commitments and all three participants in this group were struggling with their weight and health.

Terry had been managing his diabetes for the last twelve years but had recently been put onto insulin, which had led to a weight gain of one and a half stone. This was in conflict with his self-image as someone who had succeeded in coping with his condition.

I don't like the additional weight at the moment but I'm not going to do anything that's short sharp shock treatment because it won't be the answer for me...I've put weight on...I don't like the look of it...I've got to get my head round it. But I have the personality that nothing happens too fast; I want to work it out...

(Terry, 54)

Malcolm experienced high blood pressure, high cholesterol and breathlessness and had been actively trying to lose weight for some months. However, his self image as an older person made it difficult for him to go to the gym. Both were struggling with their current image of themselves which made it harder for them to make changes. 
It's come more as I get older, I never used to have any problems with my weight, and I used to drink a bit more then... I think as of, as you progress older you seem to fill out a bit more...it gets harder to actually lose it. I think also when you're younger...they can keep themselves a lot fitter than an older person anyway to related to going to the gym and treadmills and stuff like that, whereas an elderly person, OK they do, some will do won't they, once the weight's on them, it's a lot harder for them to lose that weight.

(Malcolm, 59)

Bill juggled two jobs to replace his wife's income, as she was unable to work due to serious health problems over the last three years. He also took on many of the household chores that she was unable to do.

I end up doing most of the cooking and some of the cleaning and ironing so a lot of my time is taken up and the time that I used to have, say five years ago, when I'd go to the gym twice a week, three times a week, spend an hour in the sauna having a laugh and a joke, I just don't have time for it at the moment. And it's just one of those things I'm afraid you know... I feel now if I'm out at the gym, I think best get on because I'm stealing time on what I should be doing.

(Bill, 59)

These brief portraits give a quick insight into how difficult it can be to prioritise weight management for some men. 
Additionally, Terry's comments illustrate how personality can affect weight management. He says that while he does not like the 'look' of his weight gain his personal approach will affect the way he chooses to make changes. This was also apparent in other participants' responses.

\subsubsection{Personal approaches to weight management}

Differences in personality are another factor that highlights the challenge of weight management services in meeting the needs of individuals. During analysis it was possible to categorise personal approaches into proactive and reactive and to explore the notion of internal (self) or external discipline relating to personality.

\subsubsection{Proactive approach}

Some participants described a proactive approach where they prioritised their health and fitness, organising their lives to reflect its importance to them. It was possible to determine a spectrum of control amongst participants with Jake demonstrating a need for a higher degree of control in his approach than most people.

I think getting into that way of not caring about what I'm doing... that made me feel like I'm out of my comfort zone, I'm not in control of everything in my life and I like having that control about aspects of my life rather than leaving it to chance. I think routine in my life personally, works much better than kind of drifting around... it is difficult to stick to, but in the long run, it makes me feel happier with myself and how my life's going. Because if anything comes up, I can 
say 'okay, I need to change this, that and the other and it will be all right' rather than 'oh no, something's happened, what do I do, what do I do?' and it all becomes hectic and makes me panic.

(Jake, 27)

Others were similarly proactive but perhaps less intensely as Chris explained how he fitted exercising into his daily life.

[after work] “We do all the kids activities...up until nine o'clock really and then it's our time then so that's when we fit in everything we've got to do and that includes that [Wii Fit].

(Chris, 44)

\subsubsection{Reactive approach}

Other participants took a more reactive approach explaining how they would 'hammer the exercise' and reduce their intake to lose weight in response to a special event or holiday coming up

Steve discussed his weight cycling over the last two to three years and recognised that his weight was not currently a priority for him.

I think I could get back to that, I think it's achievable...maybe it's down to maybe I don't want it enough, maybe I'm fairly ok with my current build.

(Steve, 29) 
Ian fell somewhere in between with a mix between making measured dietary changes and an all or nothing approach to attending the gym.

Cut down on fatty food, sweet food, go for more you know, low calorie food, smaller quantities more than anything else actually and avoid the snacking...if I've got evening commitments two or three times a week I know I can't go, I don't bother going the whole week then, you just do get out of the habit very quickly...there's no point doing the odd day here and there, it doesn't have any impact...But I find it quite easy to snap back out once I decide to (laughs), it's weird but once I know I've got the time to go to the gym, I'll snap back into that routine very quickly.

$($ Ian, 34)

Personality clearly affected approaches to weight management and another aspect of this was internal (self) or external discipline.

\subsubsection{Self discipline}

Self discipline was reported as a problem in resisting treats or knowing when to stop eating. Rick describes how his friend struggles with self-discipline and is therefore looking for novel diets rather than simply cutting down calories. Yet for Rick with his pragmatic approach it is a simple question of getting the balance right between food intake and calories burnt through activity. 
He'll be one of them who's doing diets every 6 months... try and do another crash diet and then that doesn't work, because of his diet at the end of the day, because he's greedy, he is, he'll come down and tell you he's greedy...The reasons he can't do that are, to my mind quite simple, 'cos, he takes in too many calories and he's not burning enough calories, he can go on all the fancy diets he wants but until you address that fundamental problem, you know, you're never going to sort it out...

(Rick, 30)

\subsubsection{External discipline}

Bill explained how he felt he needed external discipline from an outside source to help him manage his weight.

The most success I had in losing weight was about discipline, you know going there and sat round and in those days men didn't go to [commercial slimming group] ...it's also the discipline, you know, the moment had gone, there was nobody, apart from [wife], there's nobody saying 'hey, look at you', you know. And the brother that I lost was my best mate really and he, if he saw me now, he'd rip into me good style, he really would. And we sort of looked after each other that way when dad went. So yeah, I've had none of that, I've had none of that outside discipline, I haven't thought about it like this, I haven't had the outside discipline, I haven't had the time, there's lots of other things more important...

(Bill, 59) 
Bill is an example of someone who has a problem with his weight although he has successfully managed it in the past and is confident that he knows how to do it. It is possible to interpret his comments as recognition that he needs someone from outside of his day-to-day life to give him permission to make time for himself and hold him to account for neglecting his health. There was a commonly held perception that traditional weight management methods would not necessarily address this need.

\subsection{Gender and methods of weight management}

From the interviews it seemed that the participants placed an equal or greater emphasis on increasing physical activity than making dietary changes. None of the participants mentioned using diet alone. The comments from Phil and Terry suggest that they view counting calories, weighing oneself regularly in public and using slimming products as a feminine approach to weight management and not something that they would do.

There's a gender divide there, in terms of calorie counting, women might take a more scientific approach to it perhaps, whereas blokes, they think, 'well I shall now cut down on eating buns and drinking too much beer' and so forth.

(Phil, 50)

"I think for a lot of blokes I've worked with, probably me included, to say 'do you fancy going on some weight control regime? And 
we'll log it every week in the office.' I just don't see that at any stage happening and it never has, but the women in the office that I've worked with over many years, yeah, they're always going on the [meal replacement] this and the [commercial slimming group] that. You kind of watch if from the side."

(Terry, 54)

Jake points to societal norms as part of the problem and refer to barriers for men and women that manifest themselves in ways that perpetuate accepted gendered approaches to weight. For example, that it is more acceptable for men to exercise and less acceptable for them to 'diet'.

... a lot of men, they see weight issues and so on like that as...just as I perceive anyway, as something that only women would worry about and to do that, you're becoming a bit more feminine, surrendering your masculinity...how to actually make people comfortable enough to go for the help and not feel like they're emasculated about it and I know you'd have to change the whole perception of what you see on television and stuff like that. All these adverts for [meal replacements] and bio-active yoghurts, it all features women, you never hear men really going on about anything to do with that kind of thing, and I think that's part of the issue involved and like it's general perception.

(Jake, 27) 
This societal view is echoed in the participants' perceptions of currently available weight management services.

\subsubsection{Perceptions of available services}

Participants' responses indicated that the majority had broadly stereotypical views of what might be provided in a service designed to help people manage their weight. They also expressed the view that these were not aimed at men nor would they feel comfortable attending such a service on a personal basis although they were not against them for other people.

I haven't seen any aimed at men, they all seem to be aimed at women...so I think there probably is a stigma, that if you do attempt to go to classes you're just going to be one bloke amongst fifty women or something, so I think, for most men, they probably wouldn't go there.

(Alan, 47)

I think if they work for people, then that's fantastic, if they don't then, you know...I'd imagine it's primarily female orientated I suppose, they weigh you and they talk about, you know, 'my name is Susan and I'm obese' that sort of thing...I suppose it's all about peer group support, isn't it really and, again, if it works for people then that's a good thing.

(Phil, 50) 
By contrast, the one participant that had direct experience of attending a commercial slimming group found it a positive and helpful experience. Despite getting 'some stick at work' the benefit for Bill outweighed the stigma.

...the beauty of that [commercial slimming group] was there were people in there that were exactly the same as me... It was brilliant at the time...I got tips, I got motivation and I got the discipline and I got the success as well...out of the ordinary, there's a bloke here who's actually lost weight. You know a minority guy...I just sort of sat there going yeah I know where you've been, you know, because I've done that myself, I've pigged out because I've been down, you know I've been fed up

(Bill, 59)

Interestingly, he did not attend alone but went with his wife who was a co-member. This meant she had probably been going for some time and was established in the group, perhaps making it easier for Bill to go along too. His comments about being a 'minority guy' are also interesting because it seems that this is actually a positive factor for Bill.

In contrast for the majority of men the social discomfort that they would need to face in order to attend a traditional weight management service is compounded by different expectations from society on men and women with regard to body image. In fact, the need for a man to manage his weight at all seems to be an issue for 
uncertainty. The comment from Steve below points to overweight in men being acceptable or even desirable in some sections of society.

I think it's probably more acceptable for men to be a bit overweight...Like I sort of mix in a very sort of male, working class, go to watch the football, a lot of people I go to the football matches with, they are overweight, are happy with it or they appear happy. Whereas I think a lot of women...due to fashion maybe...want to be able to wear clothes...that don't look wrong.

(Steve, 29)

Alan's comment would suggest that the ideal body image for men, at least around forty years of age, is not precisely defined.

So you've got the teenager age group and it's all about what you see on the TV, the perfume adverts for the males is six-packs and stuff like that and it's all that type of appearance. I'm in my 40s, so you start wondering what's the appearance of a typical 40 year old should be, mid-life crisis. I don't know.

(Alan, 47)

It is in this context of gender that attitudes to help seeking were explored. 


\subsection{Seeking help}

When asked about seeking help for weight management the clear response from participants was that they would only ask their General Practitioner (GP) if there was also a medical reason to attend. This was related to perceived personal responsibility. Past experience with health care professionals and health history also had a bearing. Participants described how they would turn to family and friends for support and information or seek to self-educate via a range of sources, at least in the first instance.

\subsubsection{Personal responsibility}

There was a common and strongly held view that weight management was a personal responsibility, clearly illustrated by Terry.

But in respect of being overweight my attitude would be, 'I'll sort this myself'. So I wouldn't look, I'm sure I wouldn't look, to outside assistance [GP]. I believe that, unless you've got a medical condition, if you're just plain overweight because you're not exercising enough and eating too much and the wrong things, then, yeah, that is my outlook. You should sort it yourself...but that's a male outlook, I suspect it strongly is. A lot of my friends don't like seeking any sort of advice or help from the NHS. We just sort it, or in some cases we don't sort it.

(Terry, 54) 
Participants would not be willing to seek help for a problem that they viewed was of their own making, although Phil did comment that some people might need more support than others.

Interviewer: And do you feel that managing your weight is down to the individual very much or...?

Fundamentally, it has to be, however some people are disadvantaged...because of their circumstances or perhaps the way they perceive themselves and the world, they may lack self esteem...I guess trying to eat healthily in this day and age isn't that easy, there's so many distractions around.

(Phil, 50)

Another barrier to seeking help was the attitudes held by participants towards the role of health care services.

\subsubsection{Health care services}

A reluctance to seek help for weight management was linked to a perception that on its own it was not a good enough reason to trouble the health service.

If I thought it was more a medical condition and rather than something I could manage myself. Or affecting my health...I know doctors do give advice on diet and things like that but I'd only go to the doctors as I said if it was actually looking at a medical method or something. (Ian, 34) 
This was related to feelings around personal responsibility but some responses went a little deeper and touched on the social acceptability of attending the doctor's.

Terry relates how his contemporaries would be likely to tease him for attending the doctor's purely about weight because this would be seen as attending for cosmetic reasons.

...There's a certain element about wasting people's time, they've got better things to do than, if you like, assist me with my weight problem which I'd view as being my own responsibility. I got it there so I should sort it out. There's probably also some feeling of, the wrong word, but failure. That in going seeking help, you know, I'm admitting that I don't know what to do and I feel as though, certainly with my weight, I've always known what to do. There's also I suppose that kind, almost a pressure from the male world that you've to see, oh whatever, the doctors about your weight? Come on. My responsibility, that's how I'd see it. Last resort go and get assistance on anything really.

(Terry, 59)

For Steve, however, there is no hesitation in approaching his doctor for weight management or any other type of help. 
I'd probably speak to my friends and family first but I've no issues with contacting my GP about it...I don't think everybody's in the luxury where they've got a good GP, a friendly GP, I've got a friendly GP who I would have no issues about going to see her for anything, anything health, weight related, anything at all, no.

(Steve, 29)

Comparing Terry's views to Steve's there appears to be evidence of generational differences in outlook related to the social acceptability of men asking for help with their health.

The decision to seek help was also influenced by past experiences and existing relationships between participants and health care professionals.

\subsubsection{Previous experiences of seeking help}

Participants related how past experiences affected their decision making process in seeking help, with some having positive experiences and some less so as related by Malcolm.

I approached the doctor...went to see the dietitian nurse in my doctor's surgery...I had to do a daily chart...but it just didn't work so I lost heart...”

Interviewer: Would you consider going back to your GP and asking for support with weight management? 
“I don't think so...no, because all she did was say '...you should do that, here you are, take that chart away and fill it in, come back and see me in a month's time'...that was it...and she said 'oh well you know, you're overweight, get on with it, sort yourself out' sort of thing...but I just didn't make a follow-up appointment...she didn't give me no enthusiasm to push myself either. I just had the one appointment.

(Malcolm, 59)

Terry recognised that he was more likely to attend now that he was more familiar with the process due to managing his health condition.

Based on how I was prior to the diabetes...I can pretty much categorically say that I wouldn't approach them. I'm not very good at going to see the doctor. I've improved a lot 'cos of diabetes but, something went wrong with my big toe last week (laughs) and it was pretty horrible... but I think unless I'm a bit of a stretcher case that's how I view going to the doctor. I did go to the doctor on Monday because I had a horror night with it on the Sunday and it got to the point where I had to.

(Terry, 54)

The underlying reluctance to seek help was also linked to a desire for independence for many of the men who preferred to do their own research. 


\subsubsection{Other sources of help and information}

Participants described the different ways in which they would seek support or information before seeking help from health care services or other formal weight management support. These included family and knowledgeable friends as well as information gained through various media.

Jake explained how he used the internet as a resource to teach himself about fitness technique. Elsewhere he mentioned how he asked a friend from the gym to plan a nutrition programme for him.

The fitness programmes you can buy on the internet, I'd probably look at those kind of things again...like a DVD where someone's talking to you, it's like a lecture, I find those really easy to follow along, it's easier than reading a book. The books come after you've got the interest, but the actual spoken part, the breaking it down in simple terms and 'do this, do that, do the other' step-by-step, that pulls you in and gets you started on the small steps to recovery kind of thing.

(Jake, 27)

Steve also sought advice from sporty friends that he thought had particular expertise in the area of nutrition and exercise. This highlights the importance of social peers in shaping individuals' responses and approaches to weight management practice. 
First of all I would talk to friends and family about it...I've done that in the past. I've got some friends who are very sporty ...they gave me a few little hints and tips, you know [interval training to burn calories]

(Steve, 29)

Two participants mentioned national public health messages as sources of information such as Chris below.

I'm always reading...like whenever the government does new campaigns like the Change 4 Life and that sort of thing, I always make sure I read the literature for that.

(Chris, 44)

\subsection{Preferred characteristics of a weight management service for men}

These ideas were put forward in response to discussions around what the participants would like to see in a weight management service for men.

\subsubsection{Format}

With regard to format there was a desire for flexibility to fit in with the men's current lifestyles, taking into account their priorities. The three comments below describe three different preferred types of service for the different needs of three individuals. These responses also demonstrate a sliding scale of intervention. 
Jake liked to be able to pick and choose how and when to do his research and it does not seem likely that he would consider seeking formal support at all.

I think the internet, it's in our culture, in our society and everyone knows that they can find whatever they want on it now...I've never done any formal courses, I, personally, would find too...I don't know, restrictive like in terms of having to travel there, having to be there, you can do things at your own pace, I like that kind of format. (Jake, 27)

Steve preferred to be able to have some facilitated support from his employer, particularly in relation to allowing him time to dedicate to physical activity during the working day.

It would be great if employers could give employees maybe a certain amount of time in the week where they can maybe take part in physical sort of activity...so the investment in staff...would be good for the long term... benefit of the organisation they work for.

(Steve, 29)

Malcolm was looking for a more intense level of support.

...an all male setting sort of thing and get encouragement...they could talk to one another... and you could get feedback from the other men in the group. ...men only...but there again you've got to then fit it round your work...to get a group together because of 
people working different shifts or different times...for the meeting. ...I would say probably [run the group] nine to twelve months, meet about once every 6 weeks...but then also have somebody on call...if you were struggling and having a problem.

(Malcolm, 59)

For Malcolm, support from other men in a group-based format is desirable and therefore, for him, gender is important. The participants were asked whether it would matter to them whether the deliverer of the service was male or female.

\subsubsection{Gender of deliverer}

There was a varied response to this question with no definite majority either way. Again there may be generational differences, with younger men such as Jake preferring a male deliverer compared to older men such as Terry.

I think if it's another man, just purely because you can relate to the same sex, I think it would be easier. Sometimes it can be intimidating to talk about your problems with the opposite sex, so if it's another man that says 'I've gone through this and this is what I did, I'm back on the path' someone can relate to that, I personally think anyway.

(Jake, 27)

I've generally had female care, be it in terms of the dietitian, nurses, and I'm quite easy with that...thinking hypothetical in terms of now 
I've made the decision, I've got to go and seek help. Again I'd be happier with somebody who's female as opposed to male. Why? It's just the same as why don't I talk to my friends about it, male friends... but I just don't talk to my male friends about anything personal because all you get back is jibes, 'don't be such a wuss' type of thing...I'm a prime example, I'll just, you take stick and you give stick so.

(Terry, 54)

A stronger theme was a preference for expert advice delivered by a trustworthy and knowledgeable individual who had information or an approach that would work.

I don't think that would matter... as long as I viewed them as an expert in the field.

(Chris, 44)

Another question related to whether the men would prefer a group setting or oneto-one appointments.

\subsubsection{Group versus individual service}

Again there was a varied response to this question with some men happy with the idea of a mixed sex group and some preferring a men only group.

I would be happy with a group, it doesn't really matter either way...

I think you learn off other people's experiences as well as making 
just new friends and you might even form a little healthy group and you can help support each other...because you each have different scenarios to do with health.

(Alan, 47)

Rick displays a strong personal reaction against the hypothetical premise of attending a group at all for weight management. However, on reflection he concedes that it might be motivating for some.

Interviewer: Does the thought of a group put you off?

It probably would, yeah, I don't know, I don't know why but like I say, it probably would for me because it would be a shameful thing for me because I've not been like that, but you know, it might not be, it might be motivating to others, the more people there are there.

(Rick, 30)

Those that expressed a preference for an individual service, including Ian and Andy below, displayed some commonly held perceptions of group based support. These were that a group would not be personal or tailored enough to make a difference or that the dynamics of the group could affect the potential for success.

One-to-one. They just need to look at individual needs...because people who do sort of the basics anyway then a lot of the guidance isn't actually that helpful.

$(\operatorname{Ian}, 34)$ 
...at least initially one-to-one...the dynamics of groups are very hard to manage sometimes ... and there might be some sort of like competition, competitive nature in there and you know, yeah, at least to start with and then maybe like the offer of a bigger group, support group or something like that, but you know, I don't know, I don't know, that's probably from my preference.

(Andy, 39)

Similarly, Bill eloquently explains how he wanted the discipline of being held to account as an individual but does not need the potential support that a group might provide.

One-to-one, for me...because you call it support, I call it discipline...I get support at home. It's the discipline, I need somebody to say to me 'Bill you should have done this, why haven't you done that, tell me why you haven't done it?' And be honest and that's the sort of thing, a stranger can give you...And it needs somebody who isn't connected to you but is, their only connection is that and knows what they're doing as well, you know...somebody who's got your interests at heart but is professional and knows what's wrong, you know, know that it's not right and is really, by doing that, they're getting into your psyche if you like and they're getting hold of that little switch and saying 'hey, what about this', you know.

(Bill, 59) 
It is interesting to note that it was Bill, the only one of the sample to have attended a commercial slimming group, who reported finding group support very helpful in losing weight on a previous occasion. It would appear that he now has a different type of requirement based on his current set of circumstances.

In summary, there are many changing factors to take into account when attempting to design weight management services for men. These include the men themselves, their circumstances and their motivations. Implications for services attempting to address these needs will be discussed in the next chapter. 


\section{Chapter 4}

\section{Discussion}

\subsection{Introduction}

This study aimed to explore men's perceptions and attitudes towards weight management and weight management services. Within this overarching theme four objectives were set and these were achieved with the main findings summarised below.

\subsubsection{Strengths and limitations of this study}

Due to the qualitative nature of the study it is not possible to generalise the findings to the male population at large. However, the study does add to previous research and will allow the reader to draw their own conclusions in relation to the populations that they work with.

Limitations of the study are that the participants were self-selected having expressed an interest in taking part and their answers may have been subject to social desirability bias because they were aware that the researcher was a weight management advisor. Only one participant did not have a white collar role and as employees from the public sector they may have been more likely to be aware of government public health messages than other sections of society, although this is not necessarily the case. However, within the study sample a range of BMIs, ages and socio-economic backgrounds were represented and the researcher is confident that this enables a synthesis of representative views from a range of men that will add to the research base. 


\subsubsection{Perceptions and attitudes towards weight management}

The study was able to bring together in one place many previously identified research findings in line with those identified in the literature review. Briefly, the participants were typically motivated to manage their weight for health and appearance rather than BMI which was perceived as irrelevant. They also felt that the ability to take part in sports or activity to maintain fitness were more important than diet alone and this became a problem when injuries were sustained, especially recurring ones.

Changing priorities along the lifecourse relating to relationships, work and recreation presented individuals with different challenges for managing their weight. An interesting concept that was vocalised by one participant was that he considered maintaining his health through a diet and exercise regime as 'work'.

\subsubsection{Identify at what stage men take up weight management services and} why

Although the men would not attend the health services for weight management alone, they would consider it as a last resort when a weight problem became associated with other symptoms. Participants said they would consult family and friends and other sources of information such as the internet first. Flexible and expert services were a key theme with the men seeking a personalised service that went beyond the general healthy eating and exercise messages in order to make it worth their while to attend. 


\subsubsection{Explore barriers to attending weight management services}

The men in this study were clear that they felt that managing their weight was a personal responsibility and tended to be mistrustful of the weight management industry. They also viewed current services to be aimed at women and therefore uncomfortable and irrelevant to them.

\subsubsection{Use the qualitative evidence to formulate recommendations for service development to maximise accessibility and effectiveness}

A number of recommendations can be drawn from the findings to inform service development. If implemented, these will allow services to reorientate their programmes and marketing to become more relevant to men. These recommendations are set out at the end of this document.

\subsection{Individual Findings}

The following section will now systematically explain each individual finding in more detail.

\subsubsection{Health}

The men in this study viewed the concept of health as a motivator for weight management. This has been echoed in another small scale qualitative study (De Souza \& Ciclitira, 2005) which focused on men and dieting where health was considered a 'legitimate' reason to diet in contrast to the perception that women dieted mainly for cosmetic reasons relating to appearance. Participants in both studies had similar profiles, being white with predominantly white collar occupations and age ranges within 30 to 59 years. This would not always appear to 
be the case in different population groups such as blue collar workers (Egger \& Mowbray, 1993).

These findings support the view that occupational grade and socioeconomic status have an impact on men's motivations for weight management. Taking a social constructionist view this is likely to be related to how they act out masculinity (Addis \& Mahalik, 2003; Garfield, Isacco and Rogers, 2008) reinforcing the importance of providing a range of service options to allow men to feel comfortable to take part, also identified in Rowe and Basi's 2010 report into maximising the appeal of weight management services. In the report they categorised male respondents into 5 segments or profiles - these were younger men, physical men, more affluent men, lower income men and black or minority ethnic men - and suggested potential service options that could be tailored to each segments needs. Therefore weight management services wishing to engage men will need to work hard to ensure they are accessible to a range of men and that this is communicated adequately through appropriate marketing.

\subsubsection{Body Mass Index}

The men's dismissal of BMI as a definition of health was apparent. The ability of BMI alone to predict health outcomes was the subject of discussion in a review of BMI screening (Wilson \& McAlpine, 2006) where the relevance of fitness as a predictor of health outcome and not just BMI was raised. Although the scientific debate continues, this is in line with the men's view of health where they felt that being fit was more important than having a BMI in the healthy weight category. This rationalisation of BMI was taken further by one participant who suggested 
that he might be protected from the increased health risks due to being overweight because he adhered to a vegetarian diet. These health beliefs can prevent men taking action to manage their weight and therefore health professionals will need to consider how to get their message across in a different way, perhaps focusing on body composition and the fat to muscle ratio or waist circumference.

\subsubsection{Incentives}

With regard to BMI participants noted that potentially the fitter and more muscular you were, the less healthy you would be according to the scales. This attitude was also identified in Lee Monaghan's paper (2007) where height-weight charts developed by insurance companies were viewed as part of an attempt to impose irrational standardisation which the men would not conform to. This was also the finding in the current study with one participant suggesting that if the tables were more realistic, perhaps they could be used to predict life years lost and this could be reflected in the premiums, to offer an incentive for weight management.

Another participant referred to news reports that some Primary Care Trusts were considering paying people to lose weight. He compared this cost to the potential saving on health care costs for obesity related disease such as diabetes or weight loss surgery. This raises an interesting concept that perhaps some men need a more concrete, or practical reason for managing their weight than their health. Financial incentives could certainly do that, perhaps in the form of a weight loss challenge with a monetary reward. 


\subsubsection{Fitness and Injuries}

In relation to fitness, one participant displayed concern about starting a fitness regime due to his current health. Similar views were echoed in a study by Towers, Flett and Seebeck (2005) which found low self rated health was a significant barrier to exercise behaviour change rather than a potential motivator to start becoming more active. For some men, trying to get fit again seems risky and unattainable. This creates a tension between the perception of some men that increasing activity is the socially accepted method of weight management for men compared to 'dieting' and the reality that this may not be possible.

This has been echoed in other research (Weaver, Hayes, Unwin \& Murtagh, 2008) and highlights the dilemma for some men of how to manage their weight when they cannot exercise at the intensity they would like. To address this issue services designed for men could focus on promoting the physical activity aspect of weight management by providing support and advice on safe training techniques whilst at the same time providing healthy eating tips.

\subsubsection{Appearance}

Appearance was a definite motivating factor for weight management for all the men in this study with the desired image altering in relation to the participants' age. For the younger men the attainment of a healthy body with muscle definition or the bulk to be able to compete effectively in sports was more important than conforming to a healthy BMI. This is consistent with past studies that have identified a gender-based paradox where normal weight male adolescents and 
college students perceived themselves as underweight compared with normal weight adolescent and young women who perceived themselves as overweight. A more recent study further explored this paradox by examining gender and age differences in the relationship between BMI and perceived weight for 6,000 men and women between 20 and 64 years of age (McCreary, 2002). The study found that whilst women's weight misperceptions remained fairly consistent across the age groups, men's misperceptions were highest in men younger than 35 years of age.

In comparison the middle aged men in the study seemed uncertain as to what body image they should be aiming for and the older men just wanted to fit into society and avoid the label of obesity.

On this theme, a qualitative study in north east England (Weaver, Hayes, Unwin \& Murtagh, 2008) found that the men understood obesity as a description of people with centrally distributed fat and low fitness levels rather than its clinical significance. This suggests it is more likely that physical appearance and the social stigma of obesity is undesirable rather than any associated health implications. These findings were corroborated in the current study with two participants saying that they would consider liposuction to achieve their desired body image, suggesting appearance rather than health as the primary motivator. This finding is in opposition to the dominant masculine ideal that men do not lose weight for vanity alone. Further exploration is needed but clearly this phenomenon needs to be taken into account when designing weight management services for men in order to make such services appealing. 


\subsubsection{Priorities}

Prioritising weight management practices depended on where participants were along the life course and their particular personal circumstances. There was a mixed response from the participants as to whether they would take up opportunities for weight management in the work place such as an onsite gym. This is in contrast to a study by White, Conrad and Branney (2008) where men who had attended a work place weight management programme said they would not have attended if had been outside of the work place even thought they expressed strong motivation to lose weight. These men were recruited via health checks run in the work place prior to the programme's commencement which allowed them to become familiar with the team that would be running the weight management sessions. Both these factors suggest that the men's perception of the service was that it was different enough to traditional (women's) weight management services to allow them to attend without stigma. Even though the content of the course was similar to any other health service weight management course it's positioning as being for men only made it much more acceptable.

\subsubsection{Younger men}

Another theme was the impact work commitments and greater affluence had on the younger men's efforts to manage their weight. This is echoed in a Canadian study looking at the impact of gender, neighbourhood deprivation and BMI. Findings indicated an association between deprivation and increased BMI for women but the opposite was true for men with those living in affluent neighbourhoods having a higher BMI than those living in deprived neighbourhoods (Matheson, Moineddin \& 
Glazier, 2008). This difference between men and women suggests that weight management services need to be gender responsive.

\subsubsection{Middle aged men}

The middle aged men in this study, although juggling their work and family responsibilities were working with their partners to positively manage the whole family's health and weight. Perhaps men in their late 30s and early 40s are more aware of health issues or perhaps the onset of 'middle age spread' provides a window of opportunity for health promotion, especially weight management messages for men in these age groups. These findings were similar to those in Weaver, Hayes, Unwin \& Murtagh (2008) as previously mentioned. These findings confirm that any weight management service wishing to meet the needs of a range of men will need to be flexible and offer strategies for weight management that fit into daily life. Services could aim to capitalise on this age group's concerns and market themselves as a back to fitness programme with additional resources made available through various media which would allow flexible access to programme information.

\subsubsection{Gender aware services}

Gender and methods of weight management were explored, with the participant's expressing awareness of a gender divide in attitudes to weight management. They felt that it was more acceptable for men to exercise rather than diet and this extended to the acceptability of men attending currently available weight management services. They felt that the services were not aimed at them and that 
they would be out of place. This view was also aligned with the view that it was more acceptable for men to be overweight than women.

These attitudes are can be put in to context by looking at the wider picture of men's food choices which studies suggest are mediated by a range of factors especially occupational group, age and social class. Roos et al (2001) found that different occupational groups construed food differently. Working class men (carpenters) viewed food as fuel whereas middle class men (professional engineers) viewed food more as a pleasure. Another study explored gender differences in food choice using the results from a self report questionnaire carried out in over 19,000 university students in 23 countries between 1999 and 2001 (Wardle, Haase \& Steptoe, 2004). Women were more likely to report avoiding high-fat foods and eating fruit and fibre than men. They were also more likely to be dieting than men. Both men and women attached importance to healthy eating although the men less strongly.

A smaller scale study surveyed 55 Scottish men of lower socioeconomic status (McPherson \& Turnbull, 2004) and focused on the gaps in the men's nutritional knowledge and found that there was confusion about the fat content of specific foods and little awareness of the recommendations to consume more complex carbohydrates. Further, Gough and Conner (2006) found that there was mistrust and sceptisim about health messages from the government and these were seen as misleading, ideological and confusing. 
These differences in attitudes and knowledge may mean that men are less likely to be able to manage their weight through diet alone. Services may need to develop how they deliver their nutritional advice to take into account this difference between men and women to be able to dispel some of the myths around 'dieting'.

\subsubsection{Seeking help for weight management}

When the participants in this study were asked about seeking help they clearly felt that managing their weight was their own personal responsibility and seemed quite surprised that they might be expected to attend primary care health services for help with weight management. The men felt that in isolation overweight or obesity was too trivial a matter to bother the doctor with, unless associated with disease such as diabetes.

Evidence of negative attitudes from health professionals towards obese adults (Harvey, Summerbell, Kirk \& Hill, 2002) would tend to corroborate this view as socially legitimate. Similarly, media representation of men's health as fixed and stereotypical, particularly in relation to help-seeking, serves to support and perpetuate generalisations (Gough, 2006) and these in turn are assimilated by society including health care professionals (Seymour-Smith, Wetherell and Phoenix, 2002). These perceptions were echoed by the older men in this study but less so in the younger age groups where the men were much more likely to present to the doctor if they felt they had a health problem. This could be generational differences or it could simply be the difference between individuals. 
Weight management services aimed at men need to be wary of perpetuating stereotypes by making assumptions about what men want. This study's findings show that even within a small sample of men with relatively homogenous backgrounds there are many differences between them in needs and expectations.

It is relevant to note that because of their views on approaching health care services or traditional weight management services such as slimming clubs, the men were in effect somewhat isolated when considering who to approach for help with weight management. When asked where they would go for help, if they felt they needed it, they reported asking family and friends as well as doing their own research through various media. This presents an opportunity for health professionals to target men's weight management advice through novel channels such as the internet, mobile phone apps or telephone support for example.

In contrast to the majority findings, Bill's experience as the only participant to have actually attended a commercial slimming group is interesting. The fact that he accompanied his wife is also relevant as other studies have shown the significant influence that a female partner can have on a man's intention and adherence to managing his weight. Female partners are described as key in providing both practical and emotional support (De Souza \& Ciclitira, 2005; Gough, 2007). Service implications could include the development of weight management courses aimed at couples allowing men to attend with other men but also with their partners. 


\subsubsection{Preferred characteristics of a weight management service for men}

When asked about the preferred characteristics for a weight management service the men in this study had similar views to those in a paper that compared commercial and health service weight loss groups (Allan, Hoddinott \& Avenell, 2010). They found that men seemed indifferent to the leader's personal experience and placed more emphasis on expert knowledge and credibility. In addition the current study found there was no strong preference either way with regard to gender of deliverer or group versus individual service with the key requirement being expert, personalised advice.

\subsubsection{Format}

Different options for delivering weight management services need to be explored to delineate them from women's weight management services which are difficult for many men to attend due to society's perceptions of dieting as a women's problem. For example, The Waist Disposal Challenge study in Australia (Aoun, OsseiranMoisson, Collins, Newton R., \& Newton M, 2009) used educational presentations on nutrition and exercise, a monthly monitoring of BMI competition and telephone lifestyle counselling within a framework of existing Rotary clubs to examine how a community based weight management project could work to suit the health psychology of middle-aged to older men. The study found significant to moderate decreases in BMI. The monthly weight monitoring was carried out by volunteers in each club with the presentations and lifestyle coaching carried out by the researchers. This settings approach is one way to target a tailored service at a specific population group. 


\subsection{Experience of men's health promotion in Australia}

Countries other than the UK are also having to address the health differences between the genders and Australia has been at the forefront of developing men's health promotion services in recent years.

The Australian approach has been to focus on the use of settings and social marketing with such programmes as Gutbusters waist loss programme for men, the Pit Stop health screening and referral programme for men and the Men's Shed project. These approaches have been adopted in the UK with the Pit Stop programme of health checks being used locally in Knowsley. The programme developed a social marketing campaign drawing analogies between car parts and men's health concerns, for example the comparison of oil pressure to blood pressure. Age Concern have developed the Men in Sheds idea with a programme being made available in Western Cheshire recently.

However, concern has been expressed that this settings approach, despite having the best intentions, may actually reinforce negative health behaviours among some men by focusing on dominant masculine values. That is, it is ok to go to health checks in a pub, think of your body as a machine and ignore health promotion messages other than those directly targeted at men because anything else is not manly.

In conclusion, there is a need to tailor services to meet the differing health needs of specific groups of men, particularly for those with most social disadvantage. It also needs to be acknowledged that there is considerable gender variation between men. 
Re-orientating settings and social marketing approaches to be inclusive of multiple masculinities is necessary to meet the health needs of men (Smith, 2007). 


\section{Chapter 5}

\section{Conclusions}

This study has illustrated the complexity and diversity of men's perceptions and attitudes towards weight management and weight management services. It is clear, as is usually the case in health, that a 'one size fits all' approach will not be sufficient if services are to attract and engage men in health behaviour change.

However, it has been possible to draw some implications for practice that can be piloted at a local level. The main recommendations are set out below.

- Allow men to self refer to weight management services and remove the need for a health service referral.

- Develop a range of weight management services for men to allow them to choose what will fit into their lifestyle taking into account resources and existing services already available. For example:-

○ Pilot a 'Back to Fitness' style programme aimed at middle aged men with the emphasis on physical activity and safe training techniques. Ensure nutritional information is gender sensitive.

- Pilot a programme where men can attend with their partners and take part together, make it fun and take into account the differences between men and women's attitudes to food.

- Use the internet, mobile phone technology and telephone support creatively to make sure there is access to sensible, correct and interesting weight 
management advice. Develop this at a local level but also lobby the Department of Health to invest in this technology.

- Focus on body composition and fat loss rather than weight alone because the men in this study were not interested in Body Mass Index.

- Ensure marketing is targeted and addresses the concerns raised in this study that weight management is for girls! Make the service appeal to men by making it different to traditional weight management programmes to allow men to attend without stigma.

- Consider incentives - competition or monetary gain may work for some people, this could also be aligned with a workplace setting.

It is also clear that there is an ongoing need for more research in this field with the following topics suggested.

- More in depth research into men's views on appearance and body image because this was a strong motivator for weight management. If explored more deeply services may be able to tap into this desire to look good.

- The implications of long term injuries caused by exercising on men's ability to manage their weight along the life course.

- The concept of health as work and how can men fit it into their lives 
This study has identified many cross cutting themes in weight management and it is difficult for one local programme to address all the issues and to this end the researcher would also recommend the development of a regional men's weight management service network to share what works with other services and develop best practice. Findings also need to be shared at a national level with the Department of Health or Public Health England as the landscape of weight management services continues to change. For the future it is essential that the expertise and experience of local programmes is used to shape national policy for weight management. 


\section{References}

Addis, M. E. \& Mahalik, J. R. (2003) Men, masculinity and the contexts of help seeking. American Psychologist, 58 (1), 5-14

Allan, K., Hoddinott, P., \& Avenell, A. (2010) A qualitative study comparing commercial and health service weight loss groups, classes and clubs. Journal of Human Nutrition and Dietetics

Andersson, I., \& Rossner, S. (1997) Weight development, drop-out pattern and changes in obesity-related risk factors after two years treatment of obese men. International Journal of Obesity, 21, 211-216

Aoun, S., Osseiran-Moisson, R., Collins, F., Newton, R., \& Newton, M. (2009) A self-management concept for men at the community level. The 'waist' disposal challenge. Journal of Health Psychology, 14 (5), 663-674

Blake, M., Chaudhury, M., Deverill, C., Doyle, C., Erens, B., Falaschetti, E., Hirani, V., Moody, A., Prescott, A., Primatesta, P., Shelton, N., Stamatakis, E., \& Wardle, H. (2004). Health Survey for England 2003. London: The Stationery Office

Butland, B., Jebb, S., Kopelman, P., McPherson, K., Thomas, S., Mardell, J., et al. (2007) Tackling Obesities: Future Choices (Technical report): Foresight 
Bye, C., Avery, A. \& Lavin, J. (2005) Tackling obesity in men - preliminary evaluation of men only groups within a commercial slimming organisation. Journal of Human Nutrition and Dietetic,s 18 (5) 391-394

Connell, R. W. (1995) Masculinities Berkeley, CA: University of A California Press

Cook, D. G., Morris, J.K., Walker, M. \& Sharper, A. G. (1990) Consultation rates among middle-aged men in general practice over three years. British Medical Journal, 301, 647-650

Courtenay, W. H. (2000) Constructions of masculinity and their influence on men's well-being: a theory of gender and health. Social Science and Medicine, 50 (10), $1385-1401$

Cross-Government Obesity Unit, Department of Health and Department of Children, Schools and Families (2008) Healthy Weight, Healthy Lives: A crossGovernment strategy for England. London: The Stationery Office

Department of Health (2000) Press Release: ref: 2000/0187 London: The Stationery Office

Department of Health (2008) Ambitions for Health. Retrieved from Department of Health website: 
http://www.dh.gov.uk/en/Publicationsandstatistics/Publications/PublicationsPolicy $\underline{\text { AndGuidance/DH_090348 }}$

Department of Health (2010) Healthy Foundations Life-stage Segmentation Model Toolkit London: Gateway Reference 14183

De Souza, P. \& Ciclitira, K.E. (2005) Men and dieting: a qualitative analysis. Journal of Health Psychology, 10 (6), 793-804

Egger, G., \& Mowbray, G. (1993) A qualitative analysis of obesity and at-risk overweight in working men. Australian Journal Nutrition \& Dietetics, 50, 10-14

Egger, G. (2000) Intervening in men's nutrition: lessons from the GutBuster men's 'waist loss' program. Australian Journal of Nutrition and Dietetics, 57 (1), 46-49

Galdas, P.M., (2009) Men, masculinity and help-seeking behaviour. In A. Broom \& P. Tovey (Eds), Men's health: body, identity and social context (pp 63-82). Chichester: Wiley-Blackwell

Galdas, P.M., Cheater, F. \& Marshall, P. (2005) Men and health help-seeking behaviour: literature review. Journal of Advanced Nursing, 49 (6), 616-623

Garfield, C. F., Isacco, A. \& Rogers, T. E. (2008) A review of men's health and masculinity. American Journal of Lifestyle Medicine, 2, 474-487 
Gough, B. (2006) Try to be healthy but don't forgo your masculinity:

deconstructing men's health discourse in the media. Social Science and Medicine, $63,2476-2488$

Gough, B. (2007) Real men don't diet. Social Science and Medicine, 64, 326-337

Gough, B., \& Conner, M. T. (2006) Barriers to healthy eating amongst men: a qualitative analysis. Social Science and Medicine, 62, 387-395

Gray, C. M., Anderson, A. S., Clarke, A. M., Dalziel, A., Hunt, K., Leishman, J. \& Wyke, S. (2009) Addressing male obesity: an evaluation of a group-based weight management intervention for Scottish men. Journal of Men's Health, 6 (1), 70-81

Hakala, P., Karvetti, R-L., \& Ronnemaa, T. (1993) Group vs. individual weight reduction programmes in the treatment of severe obesity - a five year follow up study. International Journal of Obesity \& Related Metabolic Disorders, 17, 97102

Harvey, E. L., Summerbell, C. D., Kirk, S.F.L., \& Hill, A. J. (2002) Dietitians' views of overweight and obese people and reported management practices. Journal of Human Nutrition and Dietetics 15(5), 331-347

Health Development Agency (2002) Young Men's Health: What Works and Why? London: Health Development Agency Publications 
Retrieved $18^{\text {th }}$ February 2010 from National Institute for Health and Clinical Excellence website http://www.nice.org.uk/niceMedia/documents/youngmen_whatworks.pdf

Health and Social Care Information Centre (2010) Statistics on obesity, physical activity and diet: England 2010 Retrieved from the Information Centre NHS website:

http://www.ic.nhs.uk/webfiles/publications/opad10/Statistics_on_Obesity_Physical _Activity_and_Diet_England_2010.pdf

Indices of Multiple Deprivation, 2007 Communities and Local Government Retrieved from http://www.imd.communities.gov.uk/InformationDisplay.aspx

Key Statistics for the Isle of Anglesey April (2008) Paper number: 08/011 The National Assembly for Wales Commission

Retrieved from http://wales.gov.uk/topics/improvingservices/performance/area/anglesey/?lang=en http://www.assemblywales.org/anglesey.pdf

MacIntyre, S., Hunt, K., \& Sweeting, H. (1996) Gender differences in health: are things really as simple as they seem? Social Science and Medicine, 42(4), 617-624

Mansfield, A. K., Addis, M. E. \& Mahalik, J. R. (2003) "Why won't he go to the doctor?": The Psychology of Men's Help Seeking International Journal of Men's Health, 2(2), 93-109 
Matheson, F. I., Moineddin, R., \& Glazier, R. H. (2008) The weight of place: a multilevel analysis of gender, neighbourhood material deprivation, and body mass index among Canadian adults. Social Science and Medicine, 66, 675-690

McCreary, D. R., \& Sadava, S. W. (2001) Gender differences in relationships among perceived attractiveness, life satisfaction, and health in adults as a function of body mass index and perceived weight. Psychology of Men and Masculinit,y, 2 (2), 108-116

McCreary, D. R. (2002) Gender and age differences in the relationship between body mass index and perceived weight: exploring the paradox. International Journal of Men's Health, 1 (1), 31-42

McPherson, K. E., \& Turnbull, J. D. (2004) Scottish men's nutritional knowledge and the Scottish Executive's current dietary targets: they don't match up. British Nutrition Foundation Nutrition Bulletin, 29, 183-187

Men's Health Forum (2005) Hazardous Waist? Tackling the epidemic of excess weight in men National Men's Health Week 2005 Policy Report. London: Author Retrieved $2^{\text {nd }}$ May 2010 from Men's Health Forum website: http://www.menshealthforum.org.uk/files/images/Hazardouswaist.pdf Men's Health Forum (2008) The Gender and Access to Health Services Study Final Report London: The Stationery Office 
Miles, M.B., \& Huberman, A.M. (1994) Qualitative Data Analysis An Expanded Sourcebook ( $2^{\text {nd }}$ Edition) Sage: California

Monaghan, L. F. (2007) Body mass index, masculinities and moral worth: men's critical understandings of 'appropriate' weight-for-height. Sociology of Health and Illness, 29 (4), 584-609

National Health Service (NHS) Executive (1998). National Survey of NHS Patients: General Practice London: The Stationery Office

National Institute for Health and Clinical Excellence (NICE) (2006) Obesity: the prevention, identification, assessment and management of overweight and obesity in adults and children. Retrieved from NICE website:

$\underline{\text { www.nice.org.uk/guidance/CG43 }}$

O’Brien, R., Hunt, K. \& Hart, G. (2005) 'It's caveman stuff, but that is to a certain extent how guys still operate': men's accounts of masculinity and help-seeking Social Science and Medicine, 61, 503-516

Office of National Statistics GP Consultations Retrieved $18^{\text {th }}$ February 2010 from Office of National Statistics website: http://www.statistics.gov.uk/cci/nugget.asp?id=1109

Office of National Statistics Life Expectancy 
Retrieved $18^{\text {th }}$ February 2010 from Office of National Statistics website:

http://www.statistics.gov.uk/cci/nugget.asp?id=168

Peters, G. (2009) Step by Step Healthy Weight and Lifestyle Programme Annual Report Western Cheshire Primary Care Trust

Pope, C., Ziebland, S. \& Mays, N. (2006). Analysing qualitative data. In C. Pope \& N. Mays (Eds.) Qualitative research in health care (pp 72-74) Oxford: Blackwell Publishing

Roos, G., Prattala, R., \& Koski, K. (2001) Men, masculinity and food: interviews with carpenters and engineers. Appetite, 37, 47-56

Rosmond, R. \& Bjorntorp, P. (2000) Quality of life, overweight and body fat distribution in middle-aged men. Behavioural Medicine, 26, 2

Rowe, B, \& Basi, T. (2010) Maximising the appeal of weight management services. A report for the Department of Health and Central Office of Information. Ethnographic Social Research Options.

Seymour-Smith, S., Wetherell, M., \& Phoenix, A. (2002) 'My wife ordered me to come!': discursive analysis of doctors' and nurses' accounts of men's use of general practitioners. Journal of Health Psychology, 7(30), 253-267

Smith, J. A. (2007) Beyond masculine stereotypes: moving men's health promotion forward in Australia. Health Promotion Journal of Australia, 18: 20-25 
Towers, A. J., Flett, R. A., \& Seebeck, R. F. (2005) Assessing potential barriers to exercise adoption in middle-aged men; over-stressed, under-controlled, or just too unwell? International Journal of Men's Health, 4(1), 13-27

Wardle, J., Haase, A. M., Steptoe, A., Nillapun, M., Jonwutiwes, K., \& Bellisle, F. (2004) Gender differences in food choice: the contribution of health beliefs and dieting. Annals of Behavioural Medicine, 27 (2): 107-116

Wardle, J. \& Johnson, F. (2002) Weight and dieting: examining levels of concern in British adults. International Journal of Obesity, 26, 1144-49

Weaver, N. F., Hayes, L., Unwin, N.C., \& Murtagh, M.J. (2008) “Obesity” and “clinical obesity" men's understandings of obesity and its relation to the risk of diabetes: a qualitative study. BMC Public Health, 8, 3-11

West Cheshire Together (2010) Cheshire West and Chester Health Inequalities Action Plan . Retrieved $3^{\text {rd }}$ May 2010 from West Cheshire Together website: http://www.westcheshiretogether.org.uk/pdf/Health\%20Inequalities\%20Action\%20 Plan.pdf

Western Cheshire Primary Care Trust (2007). Adult Obesity in Western Cheshire Report http://www.wcheshirepct.nhs.uk/viewer.asp?docname=../data/Joint_Strategic_Need $\underline{\text { s_Assessment/Documents/General reports/Adult Obesity.pdf }}$ 
White, A., Conrad, D., \& Branney, P. (2008) Targeting men's weight in the workplace. Journal of Men's Health, 5 (2), 133-140

Wilson, A. R., \& McAlpine, D. D. (2006) The effectiveness of screening for obesity in primary care: weighing the evidence. Medical Care Research and Review, 63 (5), 570-598

Wolfe, B. L., \& Smith, J. E. (2002) Different strokes for different folks: why overweight men do not seek weight loss treatment. Eating Disorders, 10, 115-124

World Health Organisation (2000) Obesity: Preventing and managing the Global Epidemic. Technical Report Series, No.894 Geneva: World Health Organisation

World Health Organisation (2006) Overweight and Obesity. Factsheet No. 311 World Health Organisation. Retrieved $28^{\text {th }}$ November 2010 from http://www.who.int/mediacentre/factsheets/fs311/en/index.html

Zaninotto, P., Head, J., Stamatakis, E., Wardle, H. \& Mindell, J. (2008) Trends in obesity among adults in England from 1993 to 2004 by age and social class and projections of prevalence to 2012 Journal of Epidemiology Community Health, 0:17.doi:10.1136/jech.2008.077305

Ziebland, S. Robertson, J., Jay, J. \& Neil, A. (2002) Body image and weight change in middle age: a qualitative study. International Journal of Obesit,y 26, 1083-1091 


\section{List of Appendices}

$\begin{array}{ll}\text { 1. Topic Guide } & 100\end{array}$

2. Participant Information Sheet 102

$\begin{array}{lll}2.1 & \text { Participant Consent Form } & 104\end{array}$

3 Participant Profile Questionnaire 105

4 The five stages of data analysis using the framework approach 107

$5 \quad$ Transcript of intranet article used to recruit study participants 108 


\section{Appendix 1}

\section{Topic Guide}

A. Health and weight (do participants link weight and health and why/when does it become important to them?)

- How do you feel about your health in general?

- What does health mean to you?

- How important to you is your health?

- How do you feel about your weight?

Prompts:

Health - related to risk of disease

Appearance

Fitness/mobility

Family history e.g. diabetes

B. Family and friends (explore immediate support and influences)

- How do your family and friends feel about their weight and yours?

- How does this affect you?

C. Concerned about weight (if concerned what would they do?)

- If you were concerned about your weight what would you do?

- What would help you to manage your weight?

D. Past experiences (how do past experiences affect help-seeking behaviour?)

- What is your experience of trying to lose weight?

Prompts:

On own

Help of family/friends 
Commercial slimming programme

Health service

- What helped you or made it hard for you?

E. Health services (what role can they play in supporting men to lose weight, if any?)

- How could the health service help you to manage your weight?

Prompts:

Explore barriers

- What key elements of support would help you to do this?

Prompts:

Information

Practical tasks

Male or female practitioners

1:1 or group

- If you could design a programme of support to help you manage your weight what would it be like? 


\section{Appendix 2}

\section{Participant Information Sheet}

\section{What do men think about weight management and weight management services?}

\section{What is the purpose of the study?}

Statistics show that more people are overweight and obese now than twenty years ago, in fact this number has almost trebled in the UK. A report commissioned by the UK Government's Foresight programme predicts that this is going to continue to rise and by $205060 \%$ of men and $50 \%$ of women could be obese.

This study aims to ask what men really think about weight management and weight management services. A written report will be produced at the end of the study. The findings will give insight into a subject that is under researched and will be of particular interest to those developing weight management services.

\section{Why have I been chosen?}

You have been chosen as one of a small number of male participants $(10-15$ men), from different backgrounds to give your views on the research subject. The researcher wishes to gather information from a cross section of the population and your workplace has provided the opportunity to do this in one place.

\section{Do I have to take part?}

It is up to you to decide whether or not to take part. If you decide to take part you will be given this information sheet to keep and be asked to sign a consent form. If you decide to take part you are still free to withdraw at any time and without giving a reason. A decision to withdraw at any time, or a decision not to take part, will not affect the standard of any future care you may receive in any way.

\section{What will happen to me if I take part?}

If you do decide to take part, you will be given this information sheet to keep and asked to sign the consent form. You will then be asked to complete a participant profile questionnaire that will enable the researcher to decide whether to include you in the study. Once you have completed the participant profile questionnaire the researcher will contact you to let you know whether you will be included or not. The next stage will involve the researcher arranging a face to face interview with you that will take up to 1 hour to complete. Your height and weight will be recorded at the interview to assess your body mass index. The interview will give you the opportunity to give your views on weight management and weight management services. With your permission, the interview will be audio taped. No one will be personally identified in the final report.

What are the possible disadvantages and risks of taking part in the study? There is a small risk that some participants may feel uncomfortable or become upset during the interview especially if they have a sensitivity around their current weight or past weight management experiences. You may be disappointed if you offer to take part in the study but are not selected for interview by the researcher. 


\section{What are the possible benefits of taking part?}

You may welcome the opportunity to share your views and discuss your experiences with the researcher. By taking part, you will be contributing to the research base and the development of services that will hopefully benefit others in the future. You may also feel some satisfaction in supporting a Masters student to complete their studies.

\section{What if something goes wrong?}

If you wish to complain or have any concerns about any aspect of the way you have been approached or treated during the course of this study, please contact Professor Sarah Andrew, Dean of the School of Applied and Health Sciences, University of Chester, Parkgate Road, Chester, CH1 4BJ. Tel: 01244513055

If you are harmed through taking part in this research project, there are no special compensation arrangements. If you are harmed due to someone's negligence (but not otherwise), then you may have grounds for legal action, but you may have to pay for this.

\section{Will my taking part in the study be kept confidential?}

All personally identifiable information collected about you during the course of the research will be kept strictly confidential so that only the researcher carrying out the study will have access to such information. All person identifiable data will be kept securely in accordance with the Data Protection Act. All data collected in the interview will be coded for anonymity.

\section{What will happen to the results of the research study?}

The findings of the study will be written up into a report and potentially published in a relevant research journal. Information gained will be shared with other health care professionals working in weight management at conferences and meetings by either poster or presentation. Individuals who do participate will not be identified in any subsequent report or publication.

\section{Who is organising and funding the research?}

The researcher

\section{Who may I contact for further information?}

If you would like more information about the research before you decide whether or not you would be willing to take part, please contact the researcher, Paula Thorp c/o Alison Morgan, Administrative Assistant,University of Chester, Department of Biological Sciences, Parkgate Road, Chester CH1 4BJ Tel: 01244513090 or email 0517487@chester.ac.uk

Thank you for your interest in this research. 


\section{Appendix 2.1}

\section{Participant Consent Form}

Title of Project:

What do men think about weight management and weight management services?

\section{Name of Researcher:Paula Thorp}

Please tick the box if you agree with the statement:

1. I confirm that I have read and understood the participant information sheet for the above-named study and have had the opportunity to ask the researcher any questions.

2. I understand that my participation is voluntary and that I am free to withdraw from participating in the study at any time, without giving any reason and without my rights being affected.

3. I agree to my interview being audio-recorded for the purposes of this research project.

4. I agree to take part in the above study.

5. I agree to have my height and weight recorded, if I am selected for the interview

6. I understand that I may not be selected for the interview due to the small number of participants required for the study.

7. I agree to the researcher retaining my personal information until the study is completed (by $1^{\text {st }}$ November 2010) so that I can be invited to take part in the study at a later date, should a place become available.

\begin{tabular}{lll}
$\overline{\text { Name of Participant }}$ & $\overline{\text { Date }}$ & $\overline{\text { Signature }}$ \\
\cline { 1 - 1 } & $\overline{\text { Date }}$ & $\overline{\text { Signature }}$
\end{tabular}

(1 for participant; 1 for researcher) 


\section{Appendix 3}

\section{Participant Profile Questionnaire}

What do men think about weight management and weight management services?

Thank you for giving your consent to take part in the above named study.

In order to gain the views of a varied cross section of respondents it is necessary for the researcher to decide whom to include in the study based on a participant profile. These questions will allow the researcher to select individuals and invite them to take part in the next stage of the study. To ensure the study is manageable and practical a maximum of 10-15 men will be invited to participate.

Please complete and return this questionnaire to the researcher with your consent form either in person on. (day/date) (where) or via the prepaid envelope provided with this information pack.

\section{Participant Profile Questionnaire}

ID No. Office Use Only

First Name

Surname.

Date of Birth.

Postcode.

Ethnicity (please circle)

White -

British

A

Irish

B

Any other White background C

\section{Mixed -}

White and Black Caribbean D

\section{Other ethnic groups -}

White and Black African E

White and Asian F

Chinese

\section{$\mathrm{R}$}

Any other ethnic group $\mathrm{S}$

Any other mixed background $\mathrm{G}$

\section{Not Stated -}

Not stated

\section{Asian or Asian British -}

$\begin{array}{ll}\text { Indian } & \mathrm{H} \\ \text { Pakistani } & \mathrm{J} \\ \text { Bangladeshi } & \mathrm{K}\end{array}$

Any other Asian background L

Your height.

Your weight.

Body Mass Index (BMI) Office Use Only 
Are you currently or have you previously attended the Step by Step Healthy Weight and Lifestyle Programme? Please circle Yes No

Marital Status

Are you:

Married $\square$ Single $\square \quad$ Divorced $\square \quad$ Living with a $\square$ Partner

\section{Your Occupational Role}

What is your job title?

Please give a brief description of your job role

\section{Your Health}

Have your or any member of your family ever had any of the following:-

Heart disease

$\square$ Raised blood pressure

Raised cholesterol

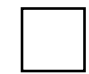

Diabetes

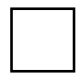

Stroke
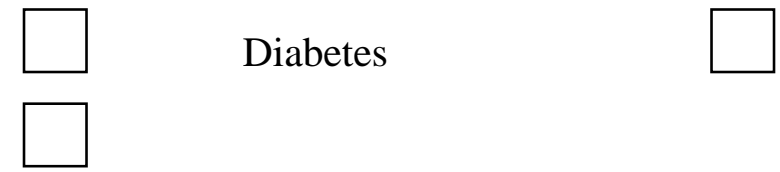

\section{PLEASE NOTE THAT THE RESEARCHER WILL CHECK YOUR HEIGHT AND WEIGHT TO ENSURE ACCURACY IF YOU ARE SELECTED FOR INTERVIEW}

\section{Thank you for completing this questionnaire.}

If you have any queries or would like more information please contact me:-

Paula Thorp

Researcher

Postgraduate Student

c/o Alison Morgan, Administrative Assistant

Department of Biological Sciences

University of Chester

Parkgate Road

Chester

CH1 4BJ

Tel: 01244513090 (9-5pm, please leave a message out of hours)

Email:0517487@chester.ac.uk 


\section{Appendix 4}

\section{The five stages of data analysis using the framework approach}

Familiarisation - immersion in the raw data (or typically a pragmatic selection from the data) by listening to tapes, reading transcripts, studying notes and so on, to list key ideas and recurrent themes.

Identifying a thematic framework - identifying all the key issues, concepts and themes by which the data can be examined and referenced. This is carried out by drawing on a priori issues and questions derived from the aims and objectives of the study as well as issues raised by the respondents themselves and views or experiences that recur in the data. The end product of this stage is a detailed index of the data, which labels the data into manageable chunks for subsequent retrieval and exploration.

Indexing - applying the thematic framework or index systematically to all the data in textual form by annotating the transcripts with numerical codes from the index, usually supported by short text descriptors to elaborate the index heading. Single passages of text can often encompass a large number of different themes each of which has to be recorded, usually in the margin of the transcript.

Charting - rearranging the data according to the appropriate part of the thematic framework to which they relate and forming charts. For example, there is likely to be a chart for each key subject area or theme with entries for several respondents. Unlike simple cut and past methods that group verbatim text, the charts contain distilled summaries of views and experiences. Thus the charting process involves a considerable amount of abstraction and synthesis.

Mapping and interpretation - using the charts to define concepts, map the range and nature of phenomena, create typologies and find associations between themes with a view to providing explanations for the findings. The process of mapping and interpretation is influenced by the original research objectives as well as by the themes that have emerged from the data themselves.

Taken from:

Pope, C., Ziebland, S. \& Mays, N. (2006). Analysing qualitative data. In C. Pope $\&$ N. Mays (Eds.) Qualitative research in health care (pp 72-74) Oxford: Blackwell Publishing 


\section{Appendix 5}

\section{Transcript of intranet article used to recruit study participants}

\section{“Volunteers required for men's weight study}

Would you be willing to answer some questions for a University of Chester study into men and weight management?

Any man over 18 who lives or works in Western Cheshire can take part in the study which is aimed at improving understanding of men's weight issues.

Participants will be asked some questions and will talk to the researcher in a confidential face-to-face interview for up to one hour. It will take place at a time to suit you on either, Monday 27, Wednesday 29 or Thursday 30 September. Your interview will take place in HQ, during office hours, so you will need to check that you have approval from you line manager to take part." 